\title{
Inhalation of printer-emitted particles impairs cardiac conduction, hemodynamics, and autonomic regulation and induces arrhythmia and electrical remodeling in rats
}

Alex P. Carll ${ }^{1,2,3}$, Renata Salatini ${ }^{1,4}$, Sandra V. Pirela ${ }^{3}$, Yun Wang ${ }^{3,5}$, Zhengzhi Xie'2, Pawel Lorkiewicz ${ }^{2}$, Nazratan Naeem², Yong Qian ${ }^{6}$, Vincent Castranova ${ }^{7}$, John J. Godleski ${ }^{3}$ and Philip Demokritou ${ }^{3 *}$

\begin{abstract}
Background: Using engineered nanomaterial-based toners, laser printers generate aerosols with alarming levels of nanoparticles that bear high bioactivity and potential health risks. Yet, the cardiac impacts of printer-emitted particles (PEPs) are unknown. Inhalation of particulate matter (PM) promotes cardiovascular morbidity and mortality, and ultra-fine particulates $(<0.1 \mu \mathrm{m}$ aerodynamic diameter) may bear toxicity unique from larger particles. Toxicological studies suggest that PM impairs left ventricular (LV) performance; however, such investigations have heretofore required animal restraint, anesthesia, or ex vivo preparations that can confound physiologic endpoints and/or prohibit LV mechanical assessments during exposure. To assess the acute and chronic effects of PEPs on cardiac physiology, male Sprague Dawley rats were exposed to PEPs (21 days, $5 \mathrm{~h} /$ day) while monitoring LV pressure (LVP) and electrocardiogram (ECG) via conscious telemetry, analyzing LVP and heart rate variability (HRV) in four-day increments from exposure days 1 to 21, as well as ECG and baroreflex sensitivity. At 2, 35, and 70 days after PEPs exposure ceased, rats received stress tests.

Results: On day 21 of exposure, PEPs significantly ( $P<0.05$ vs. Air) increased LV end systolic pressure (LVESP, +18 $\mathrm{mmHg}$ ) and rate-pressure-product (+ 19\%), and decreased HRV indicating sympathetic dominance (root means squared of successive differences [RMSSD], $-21 \%)$. Overall, PEPs decreased LV ejection time (-9\%), relaxation time $(-3 \%)$, tau (-5\%), RMSSD (-21\%), and P-wave duration (-9\%). PEPs increased QTc interval (+ 5\%) and low:high frequency HRV (+ 24\%; all $P<0.05$ vs. Air), while tending to decrease baroreflex sensitivity and contractility index $(-15 \%$ and $-3 \%, P<0.10$ vs. Air). Relative to Air, at both 2 and 35 days after PEPs, ventricular arrhythmias increased, and at 70 days post-exposure LVESP increased. PEPs impaired ventricular repolarization at 2 and 35 days postexposure, but only during stress tests. At 72 days post-exposure, PEPs increased urinary dopamine 5-fold and protein expression of ventricular repolarizing channels, $\mathrm{K}_{\mathrm{v}} 1.5, \mathrm{~K}_{\mathrm{v}} 4.2$, and $\mathrm{K}_{\mathrm{v}} \mathrm{7} .1$, by $50 \%$. Conclusions: Our findings suggest exposure to PEPs increases cardiovascular risk by augmenting sympathetic influence, impairing ventricular performance and repolarization, and inducing hypertension and arrhythmia. PEPs may present significant health risks through adverse cardiovascular effects, especially in occupational settings, among susceptible individuals, and with long-term exposure.
\end{abstract}

Keywords: Arrhythmia, Particulate matter, Autonomic, Electrocardiogram, Cardiac, Nanoparticles, Printers, Telemetry, Left ventricular pressure, Contractility, Repolarization, Electrical remodeling

\footnotetext{
* Correspondence: pdemokri@hsph.harvard.edu

${ }^{3}$ Center for Nanotechnology and Nanotoxicology. Department of

Environmental Health, T.H. Chan School of Public Health, Harvard University,

665 Huntington Avenue, Room 1310, Boston, MA 02115, USA

Full list of author information is available at the end of the article
}

C The Author(s). 2020 Open Access This article is distributed under the terms of the Creative Commons Attribution 4.0 International License (http://creativecommons.org/licenses/by/4.0/), which permits unrestricted use, distribution, and reproduction in any medium, provided you give appropriate credit to the original author(s) and the source, provide a link to the Creative Commons license, and indicate if changes were made. The Creative Commons Public Domain Dedication waiver (http://creativecommons.org/publicdomain/zero/1.0/) applies to the data made available in this article, unless otherwise stated. 


\section{Background}

Cardiovascular disease (CVD) is the leading global cause of mortality, and among its primary risk factors are high blood pressure and exposure to air pollution [1]. Among air pollutants, particulate matter (PM) is most consistently tied to increased cardiovascular morbidity and mortality. Globally, household air pollution causes an estimated 2.8 million deaths, and exposures to ambient PM account for 4.2 million deaths per year, $57 \%$ of which are cardiovascular in origin [2]. Multiple, often interacting, modes of action underlie the cardiovascular toxicity of PM, including enhanced sympathetic regulation, arrhythmia, oxidative stress, inflammation, vascular dysfunction, and exacerbation of both atherosclerosis and heart failure [3]. Modern sources of indoor air pollution may pose important health risks, especially in industrialized countries, where adults now spend $\approx 90 \%$ of their time indoors [4].

Engineered nanomaterials (ENMs), which have at least one dimension in the nanoscale $(1-100 \mathrm{~nm})$, are synthesized and used across several scientific fields and in various cosmetics, food, building materials, and medicines. Exposures to ENMs released across the lifecycle of nano-enabled products have become inevitable. Due to their size, ENMs can bypass biological barriers, become systemic, interfere with cellular processes, and induce adverse health effects [5-15]. Despite that numerous studies have linked exposure to ambient ultrafine particles to cardiovascular dysfunction, autonomic dysregulation, and heart disease [16-19], there are only limited investigations into the cardiovascular effects of ENMs [20].

Laser printer toners are nano-enabled products widely used in office and household microenvironments [21, 22]. The authors and others have performed thorough physico-chemical and toxicological characterizations of laser printer and photocopier-emitted PM [8, 21-30], whose complex chemical makeup includes toxic constituents such as transition metals (e.g., zinc, chromium, nickel, iron, titanium, and aluminum), volatile organic chemicals (VOCs), and polycyclic aromatic hydrocarbons (PAHs). Exposures to this class of PM may lead to adverse health outcomes, as worksites with high print volumes often have indoor PM concentrations far exceeding the advised limits for ambient $\mathrm{PM}_{2.5}$ [21]. Our recent work indicates that exposure to PEPs promotes airway inflammation and microvascular remodeling [21, 28]. However, the cardiovascular effects of PEPs remain unexplored.

Exposures to PM aerosols can impair LV systolic performance, indicated by decreases in ejection fraction, fractional shortening, and-assuming unaltered systolic and diastolic pressures-maximum LV pressure slope $\left(d P / d t_{\max }\right)$ [31-35]. Declines in these markers, along with LV ejection time $[36,37]$ and contractility index (pressure-normalized $d P / d t_{\max }$ ) [35], reflect diminished LV contractility and can denote heart failure: an inability of the LV to perfuse vital tissues. PM exposure can also impede ventricular repolarization, seen on the ECG as prolonged QT and $\mathrm{T}_{\text {peak }}-\mathrm{T}_{\text {end }}$ (TpTe) [38-45], a phenotype so predictive of arrhythmia and sudden cardiac death that its appearance has banished countless pharmaceuticals from the market [46-49]. As PM and other PEPs constituents (e.g., Ni, Fe, VOCs, and PAHs) are associated with impaired ventricular contractility, heart failure, electrophysiologic defects, and arrhythmia [3, $33,50,51$ ], we sought to determine the impacts of PEPs exposures on cardiac function. Real-time LVP and ECG were continuously monitored in conscious unrestrained rats during and after whole body inhalation exposure to PEPs. We hypothesized that a 21 -day ( $5 \mathrm{~h}$ per day) exposure to PEPs would impair LV performance, induce autonomic imbalance, and impede cardiac conduction.

To the best of our knowledge, no study has yet examined cardiac mechanical function in conscious animals during inhalation exposure to an air pollutant, much less ENMs like PEPs that are released across the lifecycle of nano-enabled products. Indeed, effects of air pollutants on cardiac mechanical function have been examined after exposures upon the restoration of clean air, but post-exposure assessments may allow effects to subside with compensatory responses and/or dissipation of irritant reflexes, especially with exposures more representative of environmental concentrations. Thus, to provide the first ever assessment of conscious LV performance during a pollutant aerosol exposure, we analyzed LV systolic and diastolic function both during and after PEPs exposure in conscious un-restrained rats. Further, to unmask latent and persistent cardiac effects, at 2, 35, and 70 days following cessation of inhalation exposures to PEPs, we incorporated an acute stress-test known to markedly increase blood pressure, heart rate, and catecholamines in rats [52].

\section{Results}

\section{Characterization of PEPs exposure}

Rats were exposed to PEPs in whole-body inhalation exposure chambers as described in detail by the authors in previous publications and summarized in the Methods section below [27, 53]. An empty exposure chamber was sampled continuously throughout the study for aerosol characterization. The mean concentration of PEPS across the 21-day exposure was 0.498 million particles $/ \mathrm{cm}^{3}$ by count and $71.5 \mu \mathrm{g} / \mathrm{m}^{3}$ by mass (Table 1). These concentrations are within the range found in exposure assessments in printing equipment facilities around the world. For instance, our previous investigation of 8 copier centers in the 
Table 1 PEPs aerosol concentrations

\begin{tabular}{lllll}
\hline & Mean & SD & Min & Max \\
\hline Number concentration $\left(\# / \mathrm{cm}^{3}\right)$ & 497,569 & 96,499 & 338,818 & 684,640 \\
Mass concentration $\left(\mu \mathrm{g} / \mathrm{m}^{3}\right)$ & 71.5 & 15.6 & 43.3 & 108.4 \\
Mean mobility diameter $(\mathrm{nm})$ & 49.5 & 2.5 & 44.5 & 53.2 \\
Count median diameter $(\mathrm{nm})$ & 44.6 & 2.6 & 39.2 & 48.9 \\
Geom. Standard deviation $(\mathrm{nm})$ & 1.71 & 0.04 & 1.65 & 1.86 \\
\hline
\end{tabular}

Mean, standard deviation (SD), minimum (min), and maximum (max) daily values over the 21-day exposure

greater Boston area (USA) found weekly mean nanoparticle number concentrations reaching approximately 12 times higher than background levels (before start of printing activity), with maximum temporal emission recorded at 700 -fold higher than the background average and at levels exceeding 1,000,000 particles $/ \mathrm{cm}^{3}$ [30]. In the current study, PEPs size distributions were relatively constant across the 21-day exposure period, with daily count median diameters ranging from 39.2 to $48.9 \mathrm{~nm}$. The identified particle size distribution of PEPs was consistent throughout the exposure, with geometric standard deviation (GSD) values almost unchanged ranging from 1.65 to 1.86, with a mean of 1.71. Additional file 1: Figure S1 summarizes the particle number concentration as a function of size. The complex chemical composition of PEPs has been characterized in great detail in prior publications. Previous studies by our group have shown that printer B1 emits up to 1.3 million particles $/ \mathrm{cm}^{3}$ of varying mobility diameters ranging from 33 to $43 \mathrm{~nm}$ using the same printing protocol as in this study [27]. Further, the PEPs emitted by printer B1 under the same protocol are composed of a complex mixture of $97 \%$ organic carbon, $0.5 \%$ elemental carbon, and $2.5 \%$ metals $(\mathrm{Al}, \mathrm{Fe}, \mathrm{Cu}$, and $\mathrm{Si})$ [22].
Further, organic compounds on PEPs included both low and high molecular weight carcinogenic PAHs which are the result of interactions of catalytic metal and metal oxide nanoparticles with emitted semivolatile organic compounds $[22,23]$. The total volatile organic gaseous compounds (tVOCs) were also measured and found at low concentrations, with daily averages between $245 \pm 164$ parts per billion (ppb) and $363 \pm 162 \mathrm{ppb}[22,23]$.

Physiology before exposure All rats received clean filtered air in exposure chambers for $6 \mathrm{~h}$ each day over four successive baseline (BL) days preceding PEPs aerosol generation (Fig. 1). During BL, LVP indices and ECG morphology did not differ between the groups designated for subsequent air or PEPs exposures (Additional file 1: Table S1). The standard deviation of normal RR intervals (SDNN) was $45 \%$ higher in the PEPs group, indicating higher HRV in this group. Measures of ventricular repolarization, including uncorrected QT (measured to $\mathrm{T}_{\text {end }}$ ) and $\mathrm{TpTe}$, were comparable to historic values from male Sprague Dawley rats of the same age and sampling conditions but lacking LV catheterization (LV catheterized vs. non-catheterized rats with ECG telemetry, mean \pm SEM $\mathrm{QT}=55.9 \pm 2.1 \mathrm{~ms}$ vs. $56.5 \pm 0.8 \mathrm{~ms} ; \mathrm{TpTe}=25.5 \pm 1.8 \mathrm{~ms}$ vs. $28.1 \pm 1.6 \mathrm{~ms})$.

Autonomic and cardiac effects during exposure LVP and HRV were analyzed on all BL days and one third of exposure days ( 7 of 21 days, Fig. 1). During exposure overall, PEPs decreased the root means squared of successive RR interval differences (RMSSD), a time-domain HRV parameter that denotes relative parasympathetic influence over the heart, compared to the Air group (Table 2, $P<0.05$ ). Overall, PEPs decreased ejection time (EjeT, Table 2; $P<0.05$ vs. Air), an index of contractility

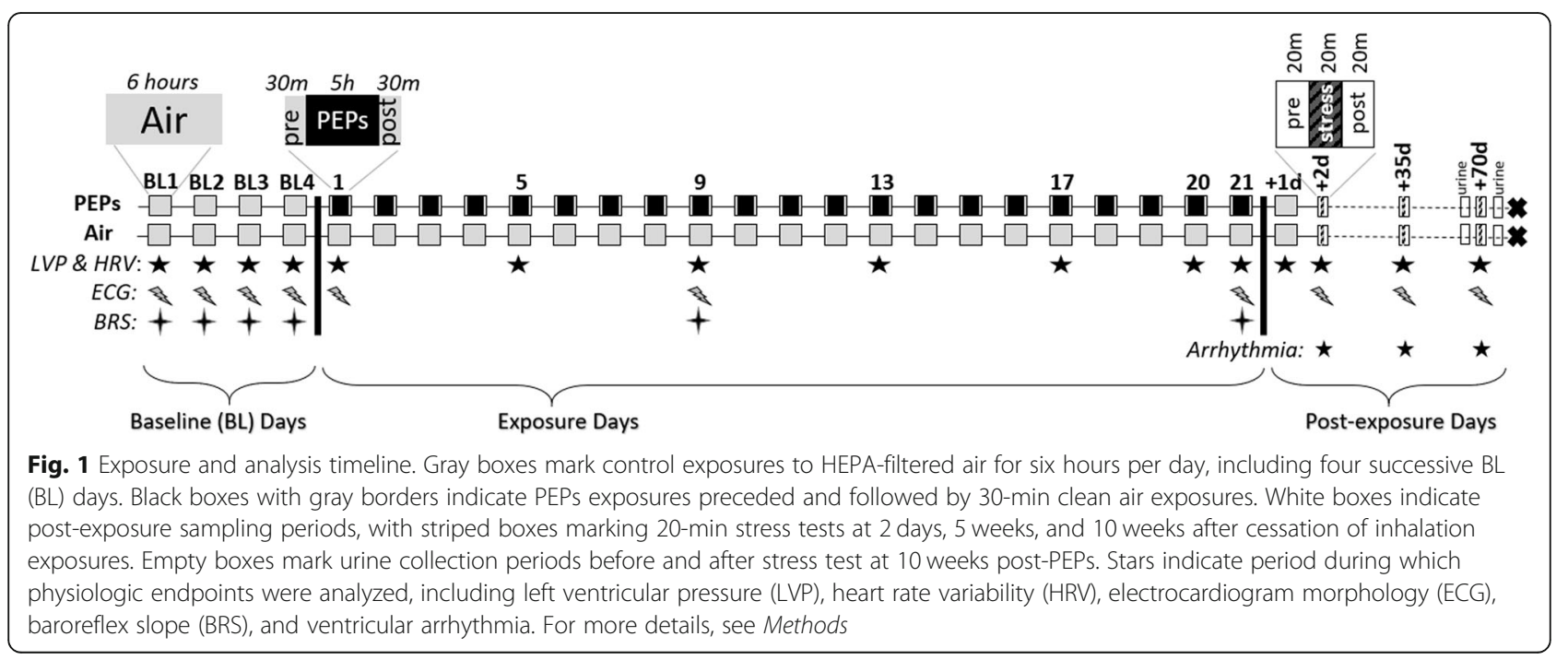


Table 2 Overall effects of PEPS on LVP, HRV, and ECG morphology before, during, and immediately after inhalation exposures and stress tests

\begin{tabular}{|c|c|c|c|c|c|c|c|}
\hline & & & \multicolumn{2}{|c|}{ Inhalation Exposure } & \multicolumn{3}{|c|}{ Stress Test } \\
\hline & & & Mid-Expo & Post-Expo & Pre-Stress & Mid-Stress & Post-Stress \\
\hline \multirow[t]{9}{*}{ LV P } & $\Delta$ from $B L$ & $\mathrm{ESP}(\mathrm{mmHg})^{\mathrm{a}}$ & - & $9.8 \pm 5.1$ & $6.5 \pm 2.5^{*}$ & - & - \\
\hline & & $\operatorname{Ctrl}\left(s^{-1}\right)^{a}$ & $-3.9 \pm 2.2$ & - & - & - & - \\
\hline & & Ejection Time $(m s)^{b}$ & $-1.1 \pm 0.5^{*}$ & $-2.8 \pm 1.1^{*}$ & $-3.3 \pm 1.7$ & $-5.4 \pm 2.1^{*}$ & $-4.6 \pm 2.4$ \\
\hline & & $\operatorname{tau}(\mathrm{ms})^{a}$ & - & $-0.31 \pm 0.13^{*}$ & $-0.34 \pm 0.17$ & - & - \\
\hline & & Relaxation Time $(\mathrm{ms})^{\mathrm{b}}$ & $-1.0 \pm 0.2^{*}$ & $-1.5 \pm 0.4^{*}$ & - & - & $-2.2 \pm 0.7^{*}$ \\
\hline & & $d P / d t_{\max }(\mathrm{mmHg} / \mathrm{s})^{a}$ & - & - & $692 \pm 260^{*}$ & - & $609 \pm 267^{*}$ \\
\hline & & $d P / d t_{\min }(\mathrm{mmHg} / \mathrm{s})^{a}$ & - & $-628 \pm 343$ & $-613 \pm 263^{*}$ & - & $-666 \pm 224^{*}$ \\
\hline & & $\operatorname{dev} P(m m H g)^{a}$ & - & - & - & - & $8.7 \pm 3.6^{*}$ \\
\hline & & \multicolumn{6}{|c|}{ No overall differences in EDP } \\
\hline \multirow[t]{5}{*}{ HRV \& BRS } & $\Delta$ from $B L$ & HR (beats/min) & - & - & $21 \pm 10$ & - & - \\
\hline & & $\mathrm{BRS}(\mathrm{ms} / \mathrm{mmHg})$ & $-0.32 \pm 0.19$ & - & & & \\
\hline & & RMSSD (ms) & $-1.0 \pm 0.5^{*}$ & $-1.2 \pm 0.6$ & - & - & - \\
\hline & & $L F / H F$ & - & $0.31 \pm 0.15^{*}$ & - & - & - \\
\hline & & \multicolumn{6}{|c|}{ No overall differences in SDNN, LF, and HF } \\
\hline \multirow[t]{11}{*}{ ECG Morphology } & $\Delta$ from $B L$ & Pdur (ms) & $-1.7 \pm 0.6^{*}$ & $-1.5 \pm 0.5^{*}$ & - & - & - \\
\hline & & $\mathrm{QT}(\mathrm{ms})^{c}$ & - & $1.4 \pm 0.7$ & - & - & - \\
\hline & & $\mathrm{QTc}(\mathrm{ms})^{\mathrm{c}}$ & - & $3.0 \pm 1.2^{*}$ & - & $5.4 \pm 2.6$ & - \\
\hline & & $\mathrm{S}$ amplitude $(\mathrm{mV})$ & $-0.031 \pm 0.014^{*}$ & - & - & - & - \\
\hline & & \multicolumn{6}{|c|}{ No overall differences in PR, QRS, STneg area, and T amplitude } \\
\hline & $\Delta$ from Pre-stress & $\mathrm{QT}(\mathrm{ms})$ & & & & $8.1 \pm 2.9^{*}$ & - \\
\hline & & QTc (ms) & & & & $9.8 \pm 2.5^{*}$ & $4.5 \pm 1.9^{*}$ \\
\hline & & ST neg area $\left(\mathrm{ms}^{*} \mathrm{mv}\right)$ & & & & - & $0.18 \pm 0.8^{*}$ \\
\hline & & T amplitude (mV) & & & & $0.052 \pm 0.017^{*}$ & $0.037 \pm 0.013^{*}$ \\
\hline & & TpTe (ms) & & & & $9.1 \pm 4.2^{*}$ & - \\
\hline & & TpTe/QT (\%) & & & & $8.5 \pm 2.2^{*}$ & - \\
\hline
\end{tabular}

Parameters were assessed as animal-matched change from the average of a 4-day BL exposure to clean air, or as animal-matched change from 20-min pre-stress period immediately before each of three stress tests. $n=4$ /group except ${ }^{a} n=3$ for Air group, and ${ }^{b} n=3$ for Air group during inhalation exposures only Interval terminus measured as T-peak

Effect estimates are presented as difference from time-matched Air control where $P<0.10$, with * denoting significant difference from Air group $(P<0.05)$

"- "denotes $P>0.10$

that is load independent and especially sensitive to cardiac myosin activation [37], and was associated with an overall trend of decreased contractility index (CtrI, Table $2 ; P<0.10$ vs. Air). Collectively, these effects suggest impairments in LV contractility during exposure to PEPs. Conversely, PEPs decreased relaxation time (RT), an inverse index of diastolic performance [35], suggesting augmented diastolic function. Across the three exposure days analyzed for ECG morphology (Fig. 1), PEPs significantly decreased $S$ amplitude $\left(\mathrm{S}_{\mathrm{amp}}\right)$ and Pduration $\left(\mathrm{P}_{\text {dur }}\right)$ overall (Table 1), suggesting accelerated atrial depolarization relative to Air $(P<0.05)$. On individual days of exposure, effects on LV performance and autonomic balance were complementary to the aforementioned effects overall (Figs. 2a-h and 3a-b). Most notably, on the final exposure day, PEPS significantly decreased HRV (SDNN and RMSSD (Fig. 2f-g), HF [Additional file 1: Figure S2], and additional variables [Additional file 1: Table S2]), and decreased EjeT and RelT (Fig. 3a-b), suggesting diminished contractility despite increased sympathetic regulation and diastolic function. Concurrently, PEPs exposure corresponded with a trend of decreased CtrI, a load -independent marker of contractility (Fig. 2c and Additional file 1: 
A LVESP

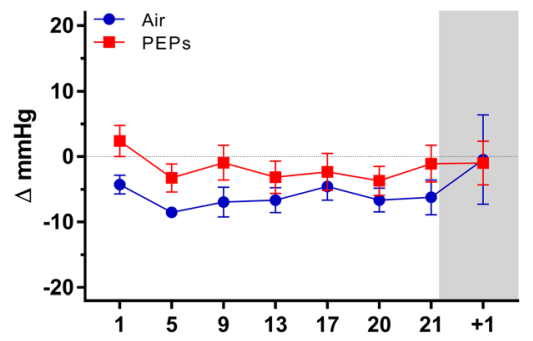

C

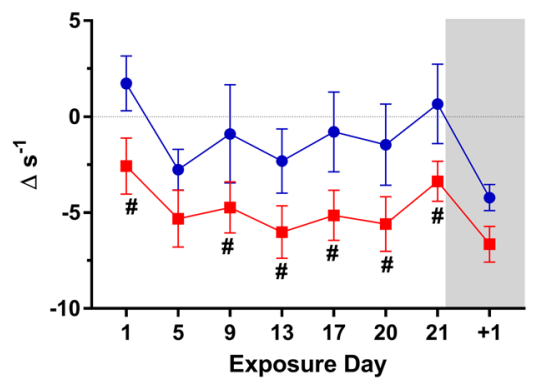

B

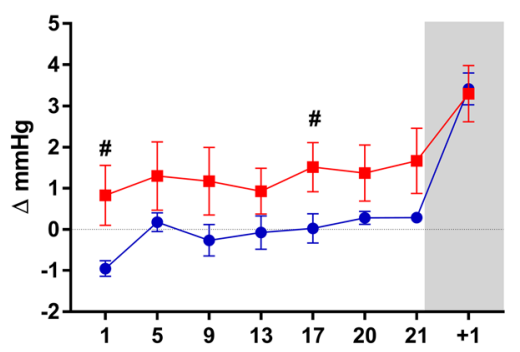

D

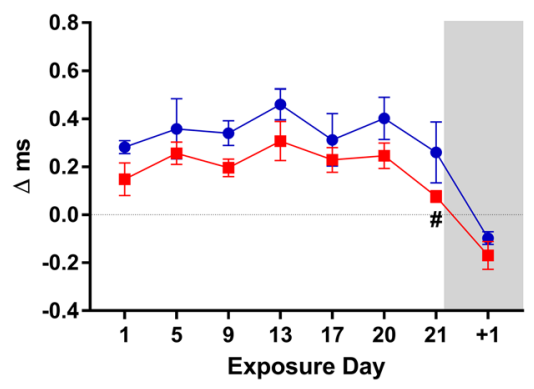

E

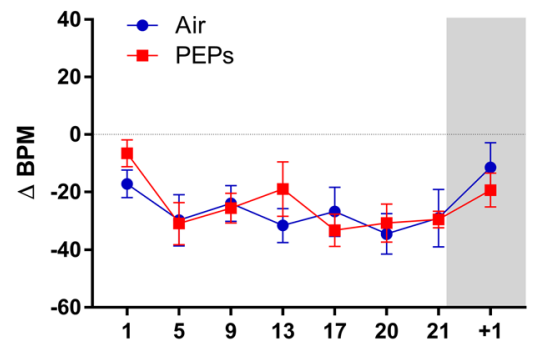

G

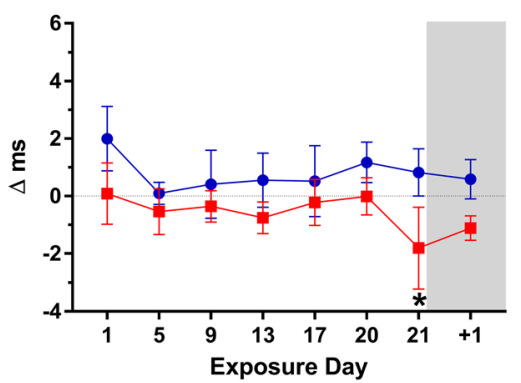

F

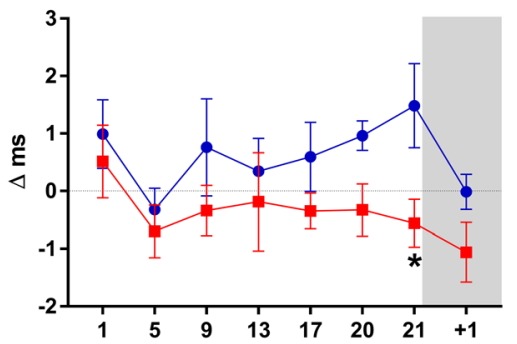

H

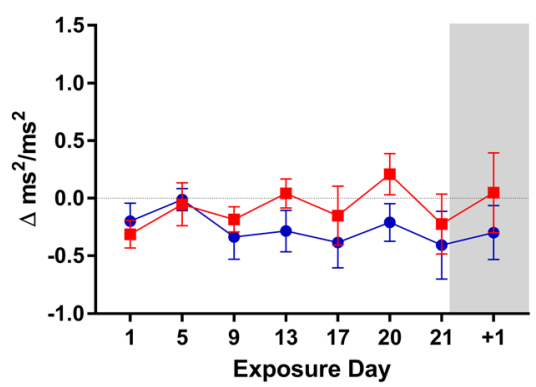

Fig. 2 Change from BL in LVP and HRV during exposure. Values calculated as mean ( \pm standard error) of each animal's change from its 4-day BL ( 5 h/day). For LVP (a-d), Air $n=3$ and PEPs $n=4$. For HRV (e-h), $n=4$ /group. Day +1 marks post-exposure day in ambulatory monitoring cages. ${ }^{\#} P<0.10$ and ${ }^{*} P<0.05$ vs. Air. BL means \pm SEM for Air and PEPs groups, respectively: LVESP $=121.7 \pm 1.4$ and $115.7 \pm 1.9 \mathrm{mmHg} ; \mathrm{LVEDP}=3.6 \pm 0.5$ and $3.2 \pm 0.9 \mathrm{mmHg} ; \mathrm{Ctrl}=114.6 \pm 0.8$ and $114.6 \pm 2.0 \mathrm{~s}^{-1} ; \mathrm{tau}=6.7 \pm 0.1$ and $6.8 \pm 0.1 \mathrm{~ms}$; heart rate $=333 \pm 4$ and $332 \pm 6 \mathrm{BPM}$; RMSSD $=3.00 \pm$ 0.34 and $4.68 \pm 0.46 \mathrm{~ms} ; \mathrm{SDNN}=8.10 \pm 0.40$ and $11.74 \pm 0.71 \mathrm{~ms}$; and $\mathrm{LF} / \mathrm{HF}=1.06 \pm 0.14$ and $1.28 \pm 0.15$

Table S2; $P<0.10$ vs. Air). Notably, trends of decreased CtrI occurred during six of the seven analyzed PEPs exposures (Fig. 2c). RT was decreased on each PEPs day compared to Air (Fig. 3b, $P<0.05$ ), and positively correlated across both exposure groups with changes in HRV, including RMSSD (Pearson's $r=0.55$ ), SDNN $(r=$ 0.47 ), and high frequency (HF, $r=0.39$, all $P<0.05$ ), indicating the PEPs augmented diastolic function in 


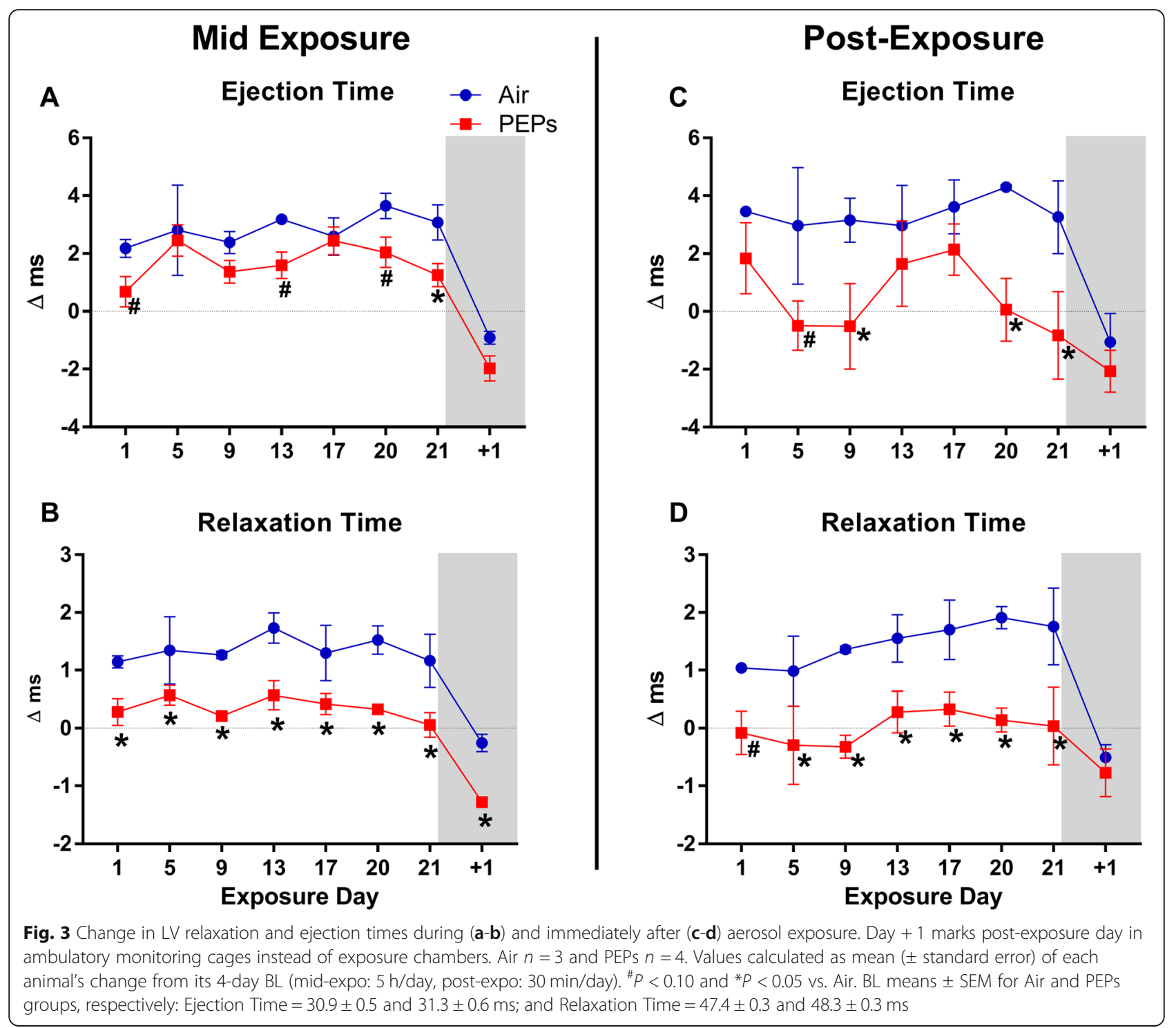

concert with sympathetic influence. Interestingly, daily CtrI values also positively correlated with HRV, but only among rats in the Air group (RMSSD, Pearson's $r=0.51$; SDNN $r=0.41$; HF $r=0.47$; LF/HF $r=-0.63$; all $P<$ 0.05 ), whereas PEPs abolished this relationship (all $P>$ 0.05), indicating PEPs disrupted the link between basal autonomic regulation and inotropy. Except for a depression in RT, PEPs-induced effects vanished 1 day after the 21-day exposure $($ day +1$)$, during ambulatory monitoring (in cages with bedding, room for movement, and food), when HR and EDP similarly increased in both groups.

Autonomic and cardiac effects early after exposure During the 30-min post-exposure phase of each analysis day (Fig. 1), PEPs increased low to high frequency ratio
(LF/HF) overall, suggesting sympathetic dominance. Concurrently, PEPs decreased EjeT and tau overall (Table 2), suggesting diminished contractility but augmented lusitropy. PEPs exposure was also associated with a significant prolongation of QTc $(P<0.05$ vs. Air, Table 2), suggesting impaired ventricular repolarization. When analyzed for day-specific effects at the postexposure phase, exposure day 21 had the most effects on LVP, including marked increases in LVESP, RPP, and $d P / d t_{\max }$, consistent with hypertension, and decreases in $d P / d t_{\text {min }}, t a u, E j e T$, and electro-mechanical coupling (EMC) that suggested diminished contractility despite enhanced lusitropy and excitation-contraction coupling (Figs. 2 and 3, Additional file 1: Figure S3 and Table S2, all $P<0.05$ vs. Air). On day 9 both tau and EjeT were significantly decreased at post-exposure (Figs. 3c and 4d; 
A

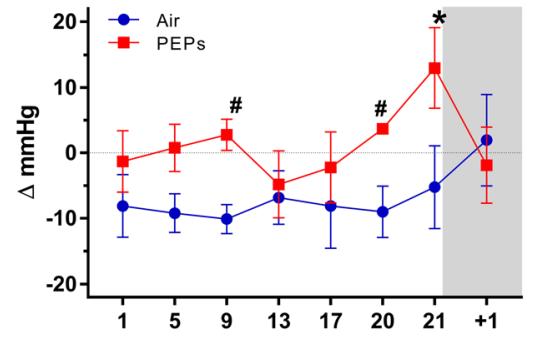

C

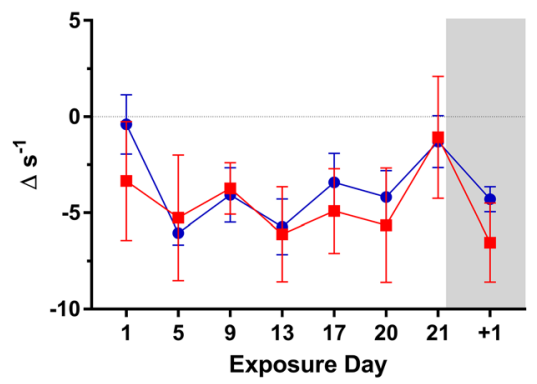

B

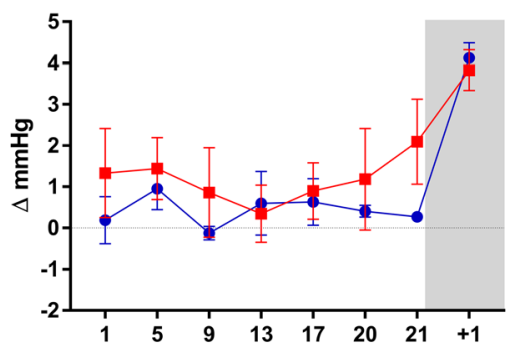

D

$\operatorname{tau}$

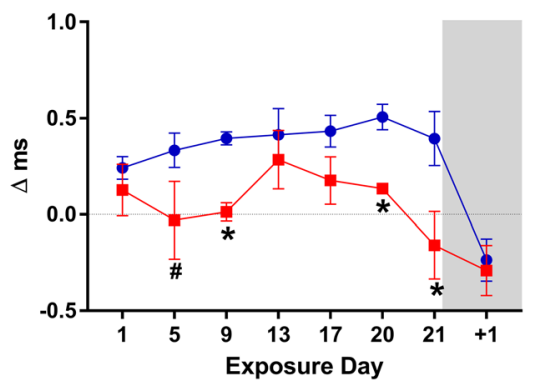

E

Heart Rate

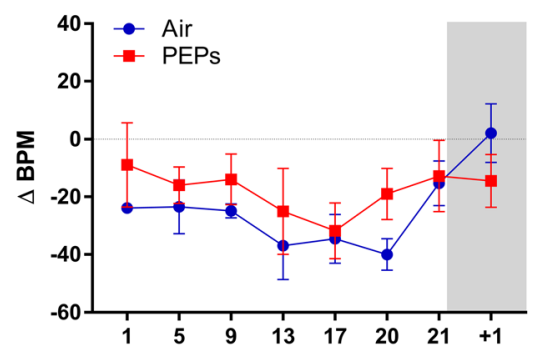

G

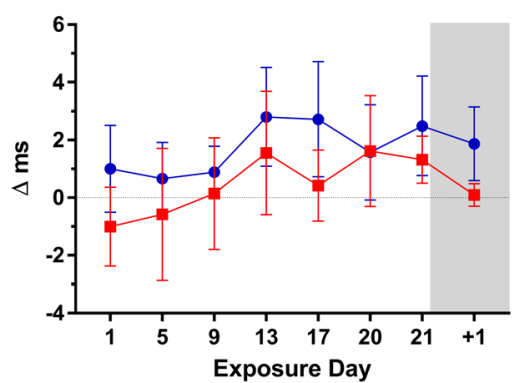

$\mathbf{F}$

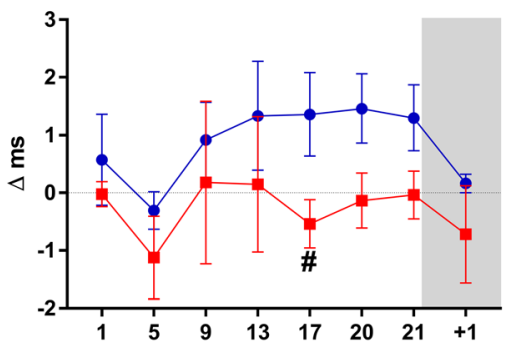

H

LF/HF

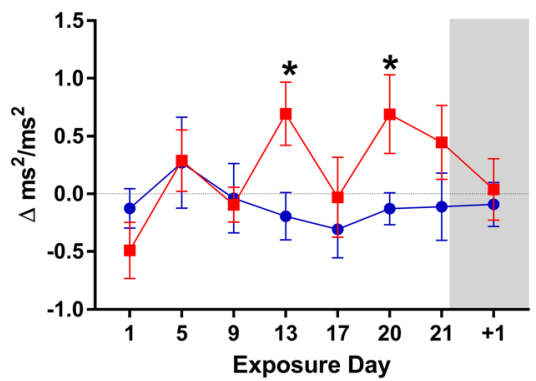

Fig. 4 Change from BL in LVP and HRV immediately after exposure. Values calculated as mean ( \pm standard error) of each animal's change from its 4-day BL (30 min/day). For LVP (a-d), Air $n=3$ and PEPs $n=4$. For HRV (e-h), $n=4$ / group. Day +1 denotes post-exposure day in ambulatory monitoring cages. ${ }^{\#} P<0.10$ and ${ }^{*} P<0.05$ vs. Air. See Fig. 2 caption or Table S1 for BL means

$P<0.05$ vs. Air), concomitant with a trend of increased LVESP (Fig. 4a, $+12.9 \mathrm{mmHg}, P<0.10$ vs. Air). On day 20, EjeT was also significantly decreased after PEPs exposure (Fig. 3c). Notably, tau at post-treatment significantly correlated with concurrent RMSSD (Pearson's $r=$
0.54, $P<0.0001)$ and HF $(r=0.41, P=0.002)$, consistent with sympatho-excitation enhancing diastolic function. In addition to day 21, PEPs significantly increased RPP on day 20 (Additional file 1: Figure S3), which was further consistent with sympathetic dominance. 
Effects on BRS Because PEPs increased LVESP on exposure day 21 and was associated with a similar trend on day 9, spontaneous baroreflex sensitivity (BRS) was assessed on these days as well as BL days (Fig. 1). In contrast with BRS slope in the control group, which was strikingly consistent with $\mathrm{BL}$, PEPs tended to decrease BRS slope during exposure overall $(P<0.10$, Table 2$)$ and diminished BRS on each individual day despite not reaching statistical significance (Additional file 1: Figure S4). Notably, daily BRS across both groups correlated strongly with HRV during the exposure phase (RMSSD $r=0.64$; SDNN $r=0.56$; HF $r=0.68$; LF $r=0.71$; all $P<0.05)$ and post-exposure phase (RMSSD $r=0.69$; SDNN $r=0.73$; HF $r=0.71$; LF $r=0.71$; all $P<0.05$ ), indicating BRS positively correlated with parasympathetic modulation of the heart.

Long-term effects on resting cardiovascular physiology Rats were sampled during 20-min resting periods before stress tests at 2 days, 5 weeks, and 10 weeks postexposure (Fig. 1). Overall, the PEPs group had significantly increased LVESP and $d P / d t_{\max }$ and decreased $d P / d t_{\min }$ relative to Air (Table 2). At 2 days postexposure, PEPs significantly increased spontaneous ventricular tachyarrhythmias (Fig. 5b) and prolonged basal LV Filling Time (Additional file 1: Table S3). PEPs continued to increase resting VPBs at 5 weeks post-exposure, when it also increased basal $d P / d t_{\max }$ and decreased basal $d P / d t_{\text {min }}$. At 10 weeks postexposure, PEPs significantly increased LVESP and $d P /$ $d t_{\max }$ and decreased RT, $d P / d t_{\min }$, and tau (Additional file 1: Table S3; $P<0.05$ vs. Air). Mean basal $\mathrm{HR}( \pm \mathrm{SE})$ was $318 \pm 7,309 \pm 4$, and $300 \pm 4 \mathrm{BPM}$ for the Air group, respectively, at day 2, week 5, and week 10 of post-exposure, with no differences from the PEPs group (Additional file 1: Figure S5).

Long-term effects on cardiovascular responses to stress Among Air rats, the stress test robustly increased HR (20-min mean \pm SEM: $496 \pm 2$ BPM on day 2, $483 \pm$ $8 \mathrm{BPM}$ on week 5 , and $468 \pm 13 \mathrm{BPM}$ on week 10). PEPs did not alter this response (Additional file 1: Figure S5). However, overall (across all stress days), PEPs increased $d P / d t_{\max }$ and decreased $d P / d t_{\min }$ during stress recovery while also accelerating RT and increasing developed pressure (devP; Table 2; all $P<0.05$ vs. Air), collectively indicating PEPs enhanced hemodynamic responses to stress. Overall, PEPs prolonged all five indices of repolarization, including QTc, during the stress challenge or recovery (Table 2). Stress tests consistently increased VPBs relative to pre-stress among both groups, with no group differences in number of VPBs during stress (Additional file 1: Figure S6). Two days after the 21-day inhalation exposure, the stress test revealed a PEPsinduced decrease in EjeT absent of any other effects on LVP or HRV (Additional file 1: Table S3), and concomitant with increases in several measures of repolarization, including QTc and TpTe (Figs. 6d and 6e). Additionally, the ratio of $\mathrm{TpTe}$ to QT (an index of repolarization heterogeneity predictive of ventricular tachycardia and fibrillation [54]) remained increased during stress recovery (Fig. 6f; all $P<0.05$ vs. Air). These effects of PEPs on repolarization were recapitulated during stress at 5 weeks after exposure (Fig. 6) and were followed during stress recovery by an increase in VPBs (Additional file 1:
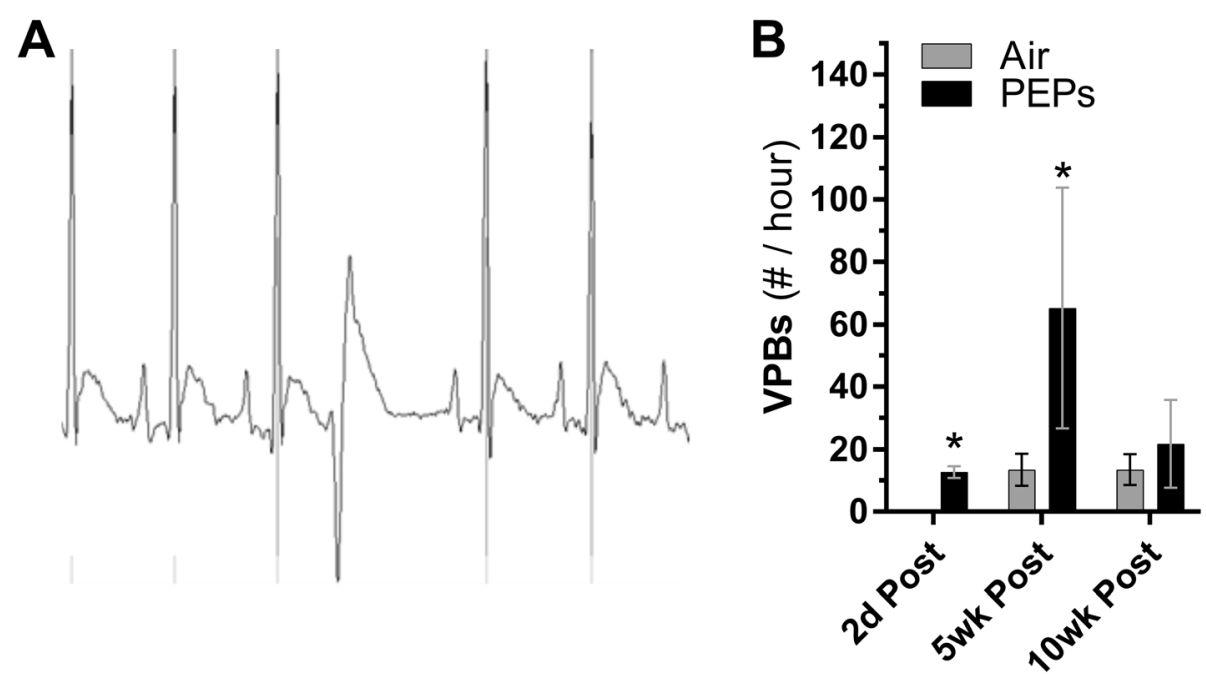

Fig. 5 Spontaneous ventricular premature beats (VBPs) after a 21-day inhalation exposure to PEPs. a, representative VPB in a PEPs- exposed rat. b frequency of VPBs among rats exposed to either filtered air or PEPs for 21 days. Values expressed as mean ( \pm SEM) count of VPBs per hour during 20-min ambulatory observation period. $N=4$ /group. ${ }^{*} P<0.10$ and ${ }^{*} P<0.05$ vs. Air 


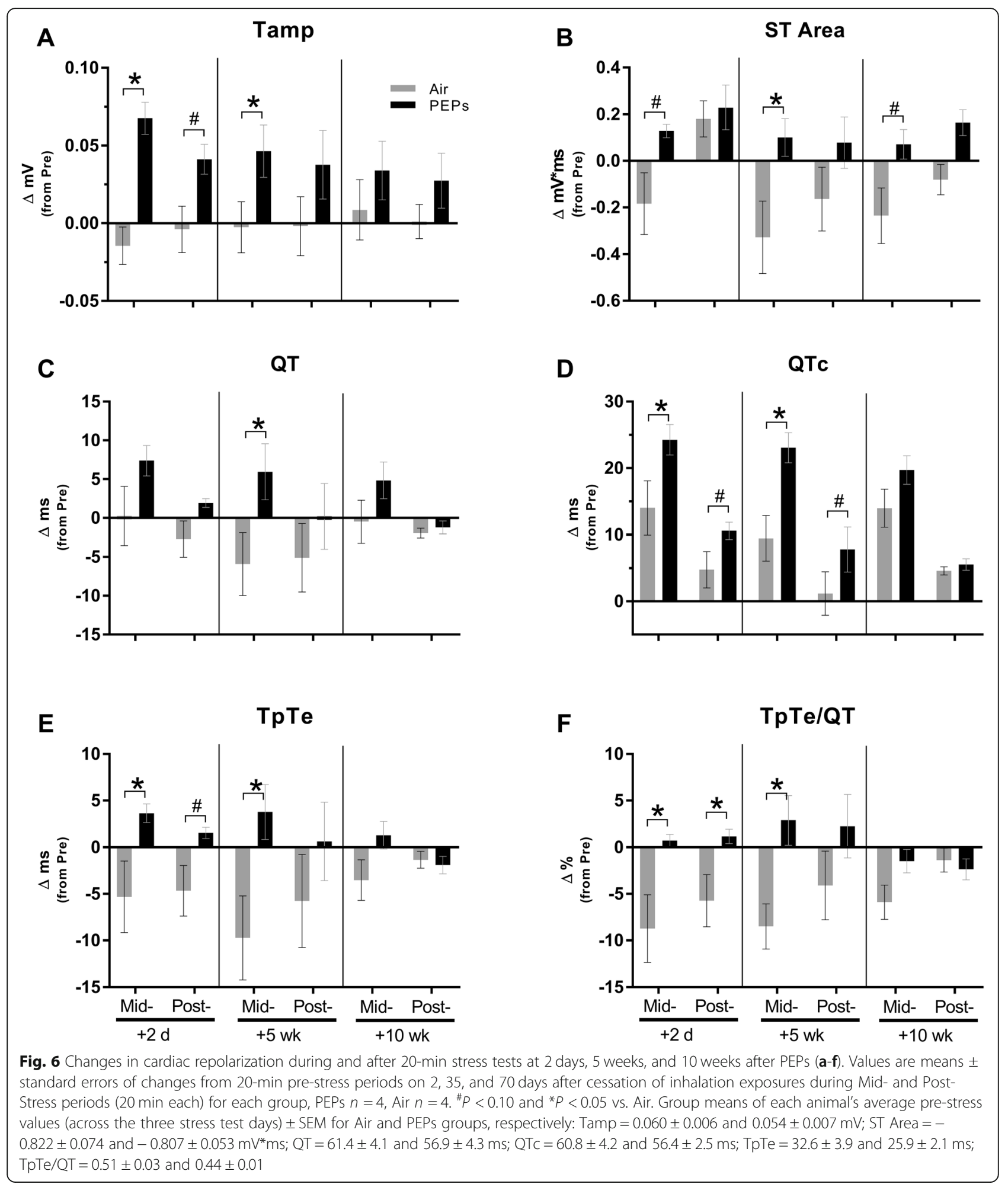

Figure S6; $P=0.05$ vs. Air), $d P / d t_{\max }$, and $\operatorname{devP}$, and a decrease in $d P / d t_{\min }$ (Additional file 1: Figure S5 and Table S3; all $P<0.05$ vs. Air). At 10 weeks postexposure, PEPs decreased tau both during and after stress (Additional file 1: Table S3; $P<0.05$ vs. Air), indicating augmented diastolic function. PEPs did not significantly alter HRV during any of the stress test days. 
Long-term effects on thermoregulation Exposure to PEPs consistently increased resting core temperature $\left(\mathrm{T}_{\text {co }}\right)$ by $0.4-0.5^{\circ} \mathrm{C}$ (Additional file 1: Figure $\mathrm{S} 7, P<0.05$ vs. Air). At 2 days post-exposure, stress decreased $\mathrm{T}_{\text {co }}$ in the PEPs group, restoring it to values comparable to the Air group. However, during the subsequent two stress tests, $\mathrm{T}_{\mathrm{co}}$ remained elevated in PEPs rats relative to the Air group.

Biochemical effects after 10-week recovery Urine samples were collected on the day before and the day after the final stress test (10 weeks post-PEPs) and assessed for changes in catecholamines and their metabolites to determine if PEPs persistently altered neurohormone excretion consistent with sympathetic dominance. In a preliminary assay, PEPs significantly increased urinary norepinephrine on the day after stress relative to the day before stress, whereas the Air-exposed group showed no such effect (Additional file 1: Figure S8). To validate these findings, we assessed a panel of biogenic amines using mass spectroscopy (Additional file 1: Figure S9). Across the two sampling days, PEPs caused an overall increase in dopamine $(P=0.05)$ as well as a trend of overall decreased metanephrine $(P=0.06)$. To determine if PEPs altered enzymatic metabolism, ratios of metabolites to parent compounds were compared between exposure groups $[55,56]$. PEPs did not significantly affect indices of catechol-O-methyltransferase (COMT) metabolism (normetanephrine / norepinephrine, 3-methyltransferase / dopamine, and metanephrine / epinephrine), monoamine oxidase (MAO) metabolism (vanillylmandelic acid / metanephrine, vanillylmandelic acid / normetanephrine), or combined aldehyde dehydrogenase 2 and MAO-A metabolism (5-hydroxyindoleacetic acid / serotonin) at either pre-stress or poststress (Additional file 1: Figure S10) [57], suggesting PEPs did not alter enzymatic metabolism despite changes in dopamine and metanephrine levels, but instead increased synthesis and/or secretion.

\section{Cardiac protein expression after 10-week recovery To} determine whether known molecular mediators of ventricular repolarization defects and arrhythmia were affected by PEPs, we assessed protein expression of voltage-gated potassium channels key to ventricular repolarization $\left(\mathrm{K}_{\mathrm{v}} 1.5, \mathrm{~K}_{\mathrm{v}} 4.2, \mathrm{~K}_{\mathrm{v}} 4.3\right.$, and $\left.\mathrm{K}_{\mathrm{v}} 7.1\right)$ at 10 weeks post-PEPs [58-60]. PEPs significantly increased LV $\mathrm{K}_{\mathrm{v}} 7.1$ (alias $\mathrm{K}_{\mathrm{v}} \mathrm{LQT} 1$ or KCNQ1; Fig. 7). Importantly, $\beta_{1}$ adrenergic receptors ( $\left.\beta_{1} \mathrm{ARs}\right)$ expedite repolarization during sympathetic stimulation by phosphorylating $\mathrm{K}_{\mathrm{v}} 7.1$ protein at serine residues [61]. Because, even weeks after exposure, PEPs impaired repolarization during stress, and because this trait is pathognomonic of concealed Long QT Syndrome 1 (LQT1) $[62,63]$ which involves mutations in -or impaired phosphorylative regulation of $-\mathrm{K}_{\mathrm{v}} 7.1$, we assessed $\mathrm{K}_{\mathrm{v}} 7.1$ serine phosphorylation through immunoprecipitation but found no differences at 10 weeks post-exposure (Additional file 1: Figure S11). PEPs also significantly increased $\mathrm{K}_{\mathrm{v}} 1.5$ and $K_{\mathrm{v}} 4.2$ expression in the RV (Fig. 7; $P<0.05$ vs. Air) without affecting LV expression, leading to a $32 \%$ greater RV:LV ratio for $\mathrm{K}_{\mathrm{v}} 1.5$ relative to the Air group $(P<$ $0.05)$, which expressed $K_{v} 1.5$ equally between the ventricles. PEPs did not affect $\mathrm{K}_{\mathrm{v}} 4.3$ expression in either ventricle (data not shown). We also assessed phosphorylation of ERK1/2 (which inversely regulates Kv1.5 expression [64] and is stimulated by adrenergic receptor activation) and expression of $\beta_{1} \mathrm{ARs}$ (which is central to sympathetic enhancements in cardiac conduction, ventricular performance [65], and repolarization [61]) but found no significant effects of PEPs (Additional file 1: Figures S12 and S13).

\section{Discussion}

Exposure to PEPs at occupationally relevant levels [30, 66] altered cardiac function, autonomic regulation, and expression of essential repolarizing ion channels. Effects included increases in LV systolic pressure, QT interval, ventricular tachyarrhythmia, and sympathetic influence, along with declines in measures of contractility and trends of decreased baroreflex sensitivity (Additional file 1: Table S5). In addition, PEPs induced cardiac electrical instability, characterized by $\mathrm{P}$ wave shortening during and after exposures, QT prolongation immediately after exposures, and spontaneous ventricular arrhythmias and stress-evoked QT prolongation at up to 5 weeks after exposures. Even at 10 weeks after exposure, PEPs induced basal systolic hypertension, decreased EjeT, and increased renal dopamine excretion concomitant with increased ventricular expression of repolarizing channels $\left(\mathrm{K}_{\mathrm{v}} 7.1, \mathrm{~K}_{\mathrm{v}} 1.5\right.$, and $\left.\mathrm{K}_{\mathrm{v}} 4.2\right)$. It is worth noting that most of the observed effects are individually associated with cardiovascular morbidity and mortality and together may synergistically increase cardiac risk [36, 47, 67, 68], particularly via hemodynamic stress, heart failure decompensation, atherogenesis, plaque rupture, thrombosis, and/or arrhythmia. Thus, our observations accord with evidence that short-term PM exposures promote CVD and specifically implicate autonomic imbalance and repolarization defects in adverse cardiac outcomes.

PEPs induced sympathetic dominance and decreased contractility during exposure. Unlike LV $d P / d t_{\max }$, which fluctuates with afterload (aortic pressure) and preload (venous return) [35], CtrI provides a stable, loadindependent in vivo marker of systolic cardiac performance [35]. Decreases in EjeT can further signify decreased contractility [37] and predict heart failure [36]. Thus, declines in both EjeT and CtrI suggested that 
$\mathrm{K}_{\mathrm{v}} 1.5$
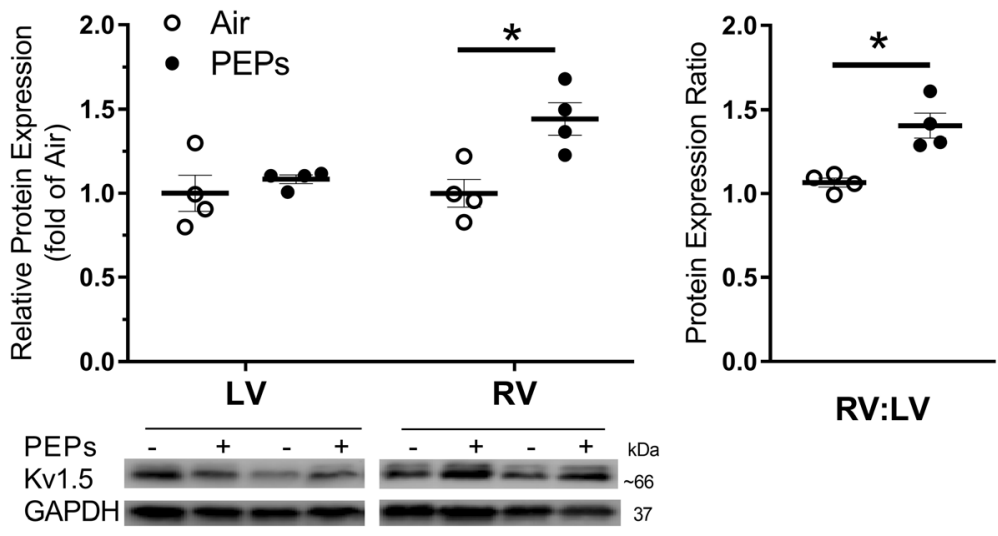

RV:LV

$\mathrm{K}_{\mathrm{v}} 4.2$
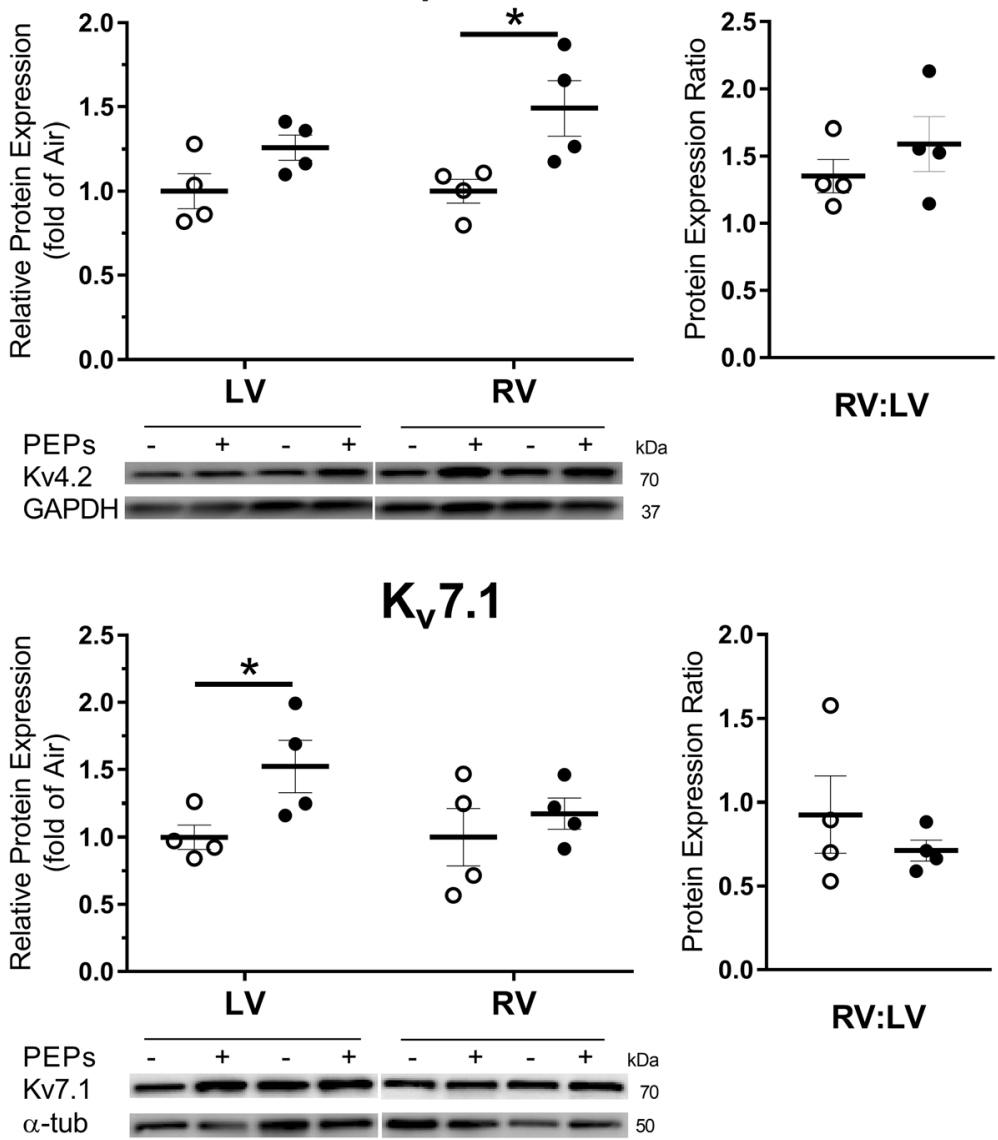

Fig. 7 PEPs increases protein expression of repolarizing voltage-gated potassium channels in right and left ventricular myocardium. Horizontal bars indicate mean $( \pm$ SEM) fold-difference from Air in expression, normalized to GAPDH. RV:LV represents the ratio of relative protein densities for GAPDH-normalized RV to LV. Individual animal values are indicated by open (Air) or closed (PEPs) circles

PEPs exposure may impair contractility despite HRV indicating enhanced sympathetic influence. These findings accord with the negative inotropic effects of exposures at $>2$-fold higher PM concentrations of carbon black [33, 34], diesel exhaust [31], or concentrated ambient
PM [69], which may decrease cardiac output while inducing catecholamine surges to provoke hypertension, pulmonary edema, and intracellular signaling toward cardiac remodeling [65]. Accordingly, PEPs impaired contractility indices during exposure especially on day 21, but these effects 
rapidly dissipated immediately after exposure when systolic pressure increased-potentially through neurohormonal compensation. Likewise, systolic pressure remained increased up to 10 weeks thereafter, when dopamine-the parent catecholamine of norepinephrine and epinephrinewas also increased.

Hypertension is the leading cause of hypertensive heart disease (including heart failure, ischemic heart disease, and LV hypertrophy) and cardiovascular mortality [1]. Even subtle increases in systolic pressure that do not qualify as clinical hypertension may cause over one third of cardiovascular deaths [70]. PM exposure promotes hypertension, heart failure, and atherosclerosis [3]. We speculate from our findings that exposure to PEPs-and perhaps PM in general- precipitates and exacerbates hypertensive heart disease by jointly impairing contractility and increasing arterial pressure. The time-course of effects indicates a mode of action underlying PMinduced heart failure exacerbation, as systolic dysfunction initiates compensatory neurohormonal and hemodynamic changes that promote pulmonary edema and decompensation. However, given the low animal numbers in this study, these findings remain relatively preliminary. More direct assessments of LV performance and pulmonary edema, and use of larger experimental groups, susceptible animal models, molecular interventions, and long-term exposures, are needed to validate our observations and further elucidate the underlying mechanisms.

The final day of PEPs exposure was accompanied by sympathetic dominance, followed immediately after exposure by increased systolic pressure $(+18 \mathrm{mmHg})$ and accelerated EMC. This slight delay between sympathetic dominance and hypertension suggest the hemodynamic effects stemmed partly from autonomic imbalance. PEPs also increased systolic pressure even at 10 weeks postexposure concomitant with increased dopamine excretion. Because enzymatic activity did not appear significantly altered, PEPs likely increased catecholamine release and/or synthesis. Although unclear from our measures, surges in dopamine immediately after exposure may have enabled the rapid recovery of contractility, increase in systolic pressure, and acceleration of EMC absent of any concurrent HRV effects, as dopamine increases contractility and systolic pressure disproportionate to its effects on pacemaker activity [71-73]. A few studies have suggested links between PM and dopamine, including one that tied "falling dust" to increased urinary dopamine and its metabolite, norepinephrine [74]. In recent human studies, annual $\mathrm{PM}_{2.5}$ levels were associated with increasing urinary dopamine and epinephrine [75], and a 9-day $\mathrm{PM}_{2.5}$ exposure corresponded with increases in systolic blood pressure and circulating tyrosine (dopamine's parent compound) and norepinephrine [76]. Dopamine and norepinephrine alter cardiovascular physiology via stimulation of dopaminergic and adrenergic receptors, and can chronically desensitize and/or downregulate these receptors via G-protein receptor kinases (GRKs) and hyper-phosphorylation [65, 77, 78]. Accordingly, PM can induce hypertension through GRK-mediated desensitization and downregulation of renal D1 dopamine receptors [79], but the role of elevated dopamine remains unknown. Moreover, as $\beta_{3}$ adrenergic and D1 dopamine receptors mediate thermogenesis $[65,77]$, catecholamine elevations may also account for the body temperature increases over the entire 10 weeks following PEPs exposure. Ultimately, with more prolonged inhalation exposures, chronic sympathetic activation may provoke cardiac structural and metabolic remodeling toward persistent declines in cardiac performance [65], as previously demonstrated [32]. Together, the effects of PEPs on HRV and catecholamines, concomitant with hypertension, contractility decrements, arrhythmia, and repolarization defects, add further evidence that exposure to PM increases risk for arrhythmia, heart failure exacerbation, and reperfusion injury, through sympathetic predominance [31, 80-84]. Moreover, our observations suggest that the adverse outcomes associated with ambient PM may translate to pulmonary exposures to ENMs.

To further elucidate the etiology of PEPs-induced hypertension, we assessed BRS on the two exposure days with greatest pressure effects (days 9 and 21). Baroreflexes provide a homeostatic defense against pressure overload during pressure increases by provoking parasympathetic dominance to slow heart rate. Spontaneous BRS tended to decrease equally during each of the two PEPs exposures and rebounded immediately afterwards. Although pressure remained unaffected during exposure, PEPs increased systolic pressure after each exposure. The concomitant pressure increase with a restoration of BRS slope suggests PEPs restored BRS at a higher mean systolic pressure through 'baroreflex resetting' [85]. We previously found in rats with metabolic syndrome that traffic PM simultaneously decreased BRS and HRV, with equivalent effects on BRS $(-0.3 \mathrm{~ms} / \mathrm{mmHg})$ and similar correlations between BRS and HRV as found here [86]. Thus, similar to other PM, PEPs exposure likely promotes hypertension not only through autonomic imbalance but also via impaired baroreflexes.

Exposure to PEPs prolonged QT, altered expression of key repolarizing potassium channels in the right ventricle $\left(\mathrm{K}_{\mathrm{v}} 1.5, \mathrm{~K}_{\mathrm{v}} 4.2\right)$ and left ventricle $\left(\mathrm{K}_{\mathrm{v}} 7.1\right)$, and increased arrhythmia long after cessation of exposures, indicating PEPs induced spontaneous tachyarrhythmia and electrical remodeling. At post-exposure on every day analyzed for ECG morphology (days 1, 9, and 21), PEPs prolonged 
QTc overall, recapitulating prior clinical and toxicological observations of the cardiac effects of PM exposure [3845]. Increases in QT and $\mathrm{TpTe}$ (a subcomponent of QT) are associated with LV remodeling and can precipitate severe arrhythmia and cardiac mortality [47, 48, 87]. Likewise, PEPs increased spontaneous ventricular premature beats at both 2 days and 5 weeks after the 21-day exposure, complementing epidemiologic associations between PM exposure and spontaneous ventricular arrhythmia [81, 88-91] and sudden cardiac arrest [92, 93]. Interestingly, aerosol exposures in noninvasive rat models of CVD typically provoke spontaneous atrioventricular block arrhythmias [45, 86, 94-98], which differ from the premature ventricular ectopy that predominates with PM exposure in humans. Yet, rodent models of surgical myocardial infarction [99-101] or genetic dilated fibrotic cardiomyopathy [102] have more consistently demonstrated tachyarrhythmias with PM exposures. Chronic LV catheterization surgery in our current study may have increased susceptibility to ventricular arrhythmia, as it leaves a small fibrotic apical scar ( $<2 \mathrm{~mm}$ diameter). LV scarring can impair conduction, propagate ectopy, and prolong QT and $\mathrm{TpTe}$ [103]; however, repolarization at baseline was no different from telemetered rats naïve of thoracic surgery. Meanwhile, PEPs impeded acceleration of repolarization during increased heart rate (i.e., repolarization reserve), manifesting as prolonged QTc, $\mathrm{TpTe}$, and $\mathrm{TpTe} / \mathrm{QT}$ during stress up through 5 weeks after exposure. To prevent arrhythmia during sympathetic-induced increases in heart rate, healthy cardiomyocytes (rat and human) accelerate repolarization by enhancing the $\mathrm{IK}_{\mathrm{s}}$ current [104] via $\mathrm{K}_{\mathrm{v}} 7.1$ phosphorylation [61]. Importantly, the long-term physiologic effects of PEPs resembled patients with concealed Long QT (LQT) Syndrome 1, who have a mutation in $\mathrm{K}_{\mathrm{v}} 7.1$ (a major phosphorylation target of $\beta_{1} \mathrm{AR}$ [61]) and prolonged QT and TpTe only during sympatho-excitation $[62,63]$. Due to an inability to decrease QT proportional to RR, patients with LQT1 have a high risk of fatal arrhythmia, especially during sympathetic activation with physical exertion or stress [105]. Although stress tests revealed QT prolongation in PEPs-exposed rats, this effect was insufficient to evoke arrhythmia. Effects on QTc, $\mathrm{TpTe}$, and arrhythmia abated by 10 weeks post-exposure, when PEPs increased expression of LV $K_{v} 7.1$, and RV $\mathrm{K}_{\mathrm{v}} 1.5$ ( $\mathrm{I}_{\text {Kur }}$ current) and $\mathrm{K}_{\mathrm{v}} 4.2$ ( $\mathrm{I}_{\text {to }}$ current) by roughly $50 \%$, and significantly altered the balance of $\mathrm{K}_{\mathrm{v}} 1.5$ expression between LV and RV, which may increase repolarization heterogeneity and arrhythmia susceptibility. Yet, QT prolongation and spontaneous arrhythmia have also been attributed to $30 \%$ decreases in ventricular $\mathrm{K}_{\mathrm{v}} 1.5$ protein expression in mice [64]. Thus, the QT-prolonging and arrhythmogenic effects of PEPs may have subsided by week 10 post-exposure due to compensatory enhancements in $\mathrm{K}_{\mathrm{v}}$ expression. Conversely, increased $\mathrm{K}_{\mathrm{v}} 1.5$ expression can increase excitability and spontaneous activation in rat cardiomyocytes [59], and increased $\mathrm{K}_{\mathrm{v}} 1.5$ in one ventricle but not the other may increase myocardial excitability by increasing dispersion and asynchronous repolarization between LV and RV [65, 106, 107]. Thus, our electrophysiological and molecular observations suggest PEPs exposure promotes cardiac arrhythmia through electrical remodeling. These findings warrant follow-up studies to quantify the prevalence and incidence of arrhythmia in printshop workers and assess the electrophysiologic effects of occupational exposures to laser printer aerosols.

Tau and RT are inverse indices of diastolic function that reflect relaxation properties of the myocardium, albeit less reliably than CtrI indicates contractile properties [35]. Tau positively correlated with HRV in PEPs rats, suggesting exposure-induced sympatho-excitation coincided with a positive lusitropic effect. The changes in tau and RT contrast with implications of impaired systolic function (decreased EjeT and CtrI) with PEPs exposure. Nonetheless, systolic and diastolic dysfunction often involve distinct molecular mediators and may occur independent of each other or in compensatory opposition of the other. Notably as well, PEPs eroded associations between HRV and CtrI, and thus may have disrupted normal autonomic modulation of inotropy. Indeed, inotropy and lusitropy can be divergently affected by protein kinase $C$ phosphorylation of cardiac troponin I upon stimulation of either adrenergic receptors or non-autonomic receptors (angiotensin or endothelin) $[108,109]$. Months after the negative inotropic effects of exposure, we did not see any effects on ventricular troponin I phosphorylation, but the relevance of these observations to preceding physiologic effects is unclear. Both elevations in sympathetic influence and declines in LV systolic function during PEPs exposure suggest pathogenic effects that may acutely and transiently exacerbate underlying heart failure.

Several limitations of this study merit discretion when interpreting our findings. Firstly, this study was designed to delineate gross effects of PEPs exposures on cardiac mechanical function and related measures. Yet, due to the demanding LV catheterization surgeries and a limited number of telemeters, the control and treatment groups were likely underpowered ( $n=4$ /group) for several endpoints. Because one Air rat had recurrent LV pressure artifacts during exposure, we excluded it from analyses at this phase of the study. Because its waveform morphology normalized after the 21-day PEPs exposure but absolute pressure values remained invalid (e.g., LVEDP $=-40 \mathrm{mmHg}$ ), LVP endpoints sensitive to absolute pressure values were excluded for this rat but time intervals (e.g., RT and EjeT) were included. The limited number of animals in this study, particularly for the pressure-derived parameters with Air $n=3$ during 
exposures, increases likelihood of Type II, and to a lesser extent Type I, errors. Yet, to optimize group comparisons, each animal's physiologic response to treatment was normalized according to its own four-day baseline. Additionally, on monitoring days after the 21-day PEPs regimen, animals were placed in ambulatory cages with bedding, food, and room to forage, potentially obscuring any effects on LVP and HRV on post-exposure days. Separately, while our findings implicate electrical remodeling and sympathetic dominance in PM-induced arrhythmia and hypertension, this study was not designed to definitively confirm these as the underlying mechanisms. More mechanistic studies are need to fully understand the potential multiple mechanisms implicated with the observed endpoints. Finally, while PEPs was associated with decreased EjeT and trends of decreased CtrI, additional measures of LV mechanical performance (e.g., pressure-volume relationships) could provide more definitive evidence toward LV systolic dysfunction; however, such endpoints require anesthetics that alter cardiac function and may thus mask treatment-related effects [110]. Ultimately, the confluence of our observations across multiple endpoints and repeated days consistently suggests adverse effects of PEPs on cardiac rhythmicity, autonomic balance, mechanical performance, and systolic arterial pressure.

As noted, the exposure concentrations of PEPs in this study are within the ranges of observed concentrations at commercial photocopy centers [21,30]. Photocopiers and laser printers use near-identical processes with nanoenabled toner formulations, and thus generate similar aerosols containing engineered nanomaterials, VOCs, PAHs, and transition metals, in addition to organic carbon particulates [21]. Importantly, transition metals and PAHs have been implicated in the adverse cardiopulmonary and autonomic effects of PM [111-113], including increased expression of $\mathrm{K}_{\mathrm{v}} 1.5, \mathrm{~K}_{\mathrm{v}} 4.2$, and $\mathrm{K}_{\mathrm{v}} 7.1\left(\mathrm{~K}_{\mathrm{v}} \mathrm{LQT} 1\right)$ in cardiac myocytes exposed to Zn PM [114]. Additionally, there is growing appreciation that ultrafine particles (aerodynamic diameter $<100 \mathrm{~nm}$ ), similar in size to PEPs, bear profound cardiovascular toxicity per-mass when compared to accumulation mode PM $\left(\mathrm{PM}_{0.1-2.5}\right)$ because of higher surface area per unit mass, and enhanced alveolar deposition and systemic translocation for direct interactions with cardiovascular cells [15]. Prior occupational studies have reported associations between PEPs exposures and oxidative stress, DNA damage, systemic inflammation, respiratory infection, and diminished pulmonary function [21]. Likewise, it is worth noting that in our recently published companion paper on the effects of PEPs on lung injury and inflammation, elevated levels of inflammation and oxidative stress markers were found in the blood of the exposed animals [53]. To our knowledge, this study is the first to report on the cardiac effects of exposure to PEPs, and in so doing, hails a novel health risk of a modern and ubiquitous technology.

\section{Conclusions}

The magnitude and breadth of the current study's findings, along with the lack of exposure control technologies in commercial printing facilities [66], bear stark implications for photocopy center employees with underlying CVD or related susceptibilities, including pregnancy. We are unaware of any current policies or regulations at local, state, or federal levels that pertain to laser-based printer or copier emissions. Our findings, with validation from further studies, may compel regulatory agencies and industry to establish occupational exposure limits and apply technological safeguards so as to decrease the levels and toxicity of printer aerosol exposures. This investigation yielded novel evidence that exposure to engineered nanomaterials released across the life-cycle of a nano-enabled product increases cardiovascular risk. Moreover, the findings represent an important advancement in inhalation toxicology, as they offer a seminal demonstration of the real-time effects of inhaled PM on LV performance in rodents. Overall, repeated exposure to PEPs impaired both cardiac mechanical performance and repolarization, and increased arterial pressure and ventricular arrhythmia. PEPs also altered multiple cardioregulatory components of the autonomic nervous system consistent with sympathetic activation, including decreased HRV, increased body temperature, and increased catecholamine production. These observations complement the mounting evidence that autonomic dysregulation mediates the pathophysiologic effects of inhaled aerosols on cardiac function. Collectively, these data demonstrate that printer emitted aerosols, and perhaps aerosols from nano-enabled products in general, present significant health risks through adverse effects on the cardiovascular system, with key implications for health risks in occupational settings.

\section{Methods}

\section{Whole-body inhalation exposure to PEPs}

Rats were housed in individual whole-body exposure chambers as previously detailed by the authors $[27,53]$. The exposed group of rats housed in individual chambers received PEPs and gaseous pollutants emitted by a laser printer B1 using the Printer Exposure Generation System (PEGS) as previously detailed by the authors [27] and described further in a recently published companion study [53]. Printer B1 was selected to generate PEPs emissions by printing a 5\%-page coverage monochrome document using standardized settings [27]. In parallel, another group of rats was exposed to High Efficiency Particulate Air (HEPA)-filtered air. An empty exposure 
chamber was sampled continuously throughout the study for aerosol characterization.

\section{Real time measurements of PEPs and other environmental conditions throughout exposure}

Particle number concentration, size distribution, temperature, relative humidity, and total volatile organic compounds (tVOC) levels were measured in real time in one of the twelve animal inhalation exposure chambers throughout the exposure durations. A scanning mobility particle sizer (SMPS Model 3080, TSI Inc., Shoreview, MN) was also used for measuring the particle number concentration and size distribution (ranging from 2.5 to $210 \mathrm{~nm}$ ) in the chamber. Real-time tVOCs levels were also monitored using a tVOC monitor (Graywolf Sensing Solutions, Shelton, CT). All the real time instruments were calibrated, and background tests were performed at the beginning of each sampling experiment. No significant variation in the temperature $\left({ }^{\circ} \mathrm{C}\right)$ and relative humidity (\%) in the inhalation animal chambers was observed throughout the exposure period.

\section{Animals and surgery for telemeter implantation}

Animals were housed and treated in accordance with the National Institute of Health guidelines for the care and use of laboratory animals. All animal protocols were approved by the Harvard Medical Area Institutional Animal Care and Use Committee (IACUC), with the surgical procedures also approved by the IACUC of DataSciences International (DSI, St. Paul, MN). Eight male Sprague Dawley rats (225-245 g, 52 days old, Charles River Laboratories, Kingston, NY) were implanted with radiotelemeters (HD-S21) capable of measuring ECG and two pressure signals. Surgeries were performed by trained surgeons at DSI (see Supplement for details). Animals were allowed 20 days to recover from surgery, after which LVP and ECG waveforms were confirmed as stable. Rats were then shipped to Harvard, where they received standard chow (irradiated PicoLab Rodent Diet 205,053, Lab Diet, St. Louis, MO) and water ad libitum in standard polycarbonate 17.6-L rat cages over a 12-h light/dark cycle. After a three-week quarantine in the animal facility, rats were acclimated to HEPA-filtered room air delivered at $1.5 \mathrm{~L} / \mathrm{min}$ in $1.4 \mathrm{~L}$ whole-body exposure chambers in a previouslydescribed exposure system [115] for $1 \mathrm{~h}$ in our Inhalation Toxicology Laboratory at $\mathrm{HSPH}$ while acquiring radiotelemetry signals.

On each of the following 4 days, rats were exposed $6 \mathrm{~h}$ to HEPA-filtered Air for BL data. Mean BL heart rate and maximal pressure upslope $\left(d P / d t_{\max }\right.$, a rough measure of contractility), were graphed on an X-Y plot and pairs of proximal rats were evenly divided among the Air-control or PEPs groups ( $n=4$ / group). On the next day, animals were placed in exposure chambers and monitored by telemetry for $6 \mathrm{~h}$, involving 30-min preexposure, 5-h exposure, and 30-min post-exposure periods, each day for 21 continuous days. Data were analyzed on all BL exposure days, days 1, 5, 9, 13, 17, 20, and 21 of exposure, and all stress test days (Fig. 2). One day after the final exposure, animals were placed in ambulatory monitoring cages (standard polycarbonate mouse cages, $25 \times 16 \times 13 \mathrm{~cm}$, or $5.2 \mathrm{~L}$ ) with bedding and limited chow (two pieces) and monitored on the exposure table at the same time of day for the same duration as the prior exposures, including pre- and post-exposure phases $(6 \mathrm{~h})$. These cages allowed for freedom of movement, including squatting on hind-limbs.

ECG and LVP ECG and LVP waveforms were analyzed for multiple endpoints on select exposure days, and treatment-related differences were determined by comparing time-matched changes from $\mathrm{BL}$ (the average of four sham exposures) between groups. In addition to analyses on BL days, HRV and LVP parameters were analyzed at four-day intervals and the penultimate day (exposures 1, 5, 9, 13, 17, 20, and 21); ECG morphology was analyzed on exposure days 1, 9, and 21; BRS was analyzed on exposure days 9 and 21; and electromechanical coupling (EMC, time from ECG Q to LV EDP, Additional file 1: Figure S15) was analyzed on exposure days 1, 9, 20, and 21. All HRV and LVP parameters were assessed over the sham exposure immediately following day 21.

ECG waveforms were analyzed with ecgAuto, v3.3 (Emka Technologies, Paris, France) for mean RR intervals, HRV, and arrhythmia as we have previously described [86, 94]. A library of 224 manually marked representative PQRST complexes was used to identify beat landmarks for ECG analyses according to previously described criteria [86]. ECG analyses were performed on all 4 BL days, inhalation exposure days 1,9 , and 21 , and all three stress test days. On exposure days, $\mathrm{T}_{\text {end }}$ was marked inaccurately by the software such that extensive manual correction was required to include $\mathrm{T}_{\text {end }}$-derived measures (e.g., Q- $\mathrm{T}_{\text {end }}$, TpTe, etc.) in any assessments of exposure-related effects. We thus defined QT on the three exposure days $\left(6 \mathrm{~h}\right.$ each) as $\mathrm{Q}-\mathrm{T}_{\text {peak }}$, which was analyzed in conjunction with $\mathrm{Q}^{-} \mathrm{T}_{\text {end }}$ on $\mathrm{BL}$ days. Conversely, because stress-test days were brief (only $1 \mathrm{~h}$ of continuous waveforms) and thus facilitated rigorous inspection and manual correction of all $\mathrm{T}_{\text {end }}$ markings, QT was defined as $\mathrm{Q}-\mathrm{T}_{\text {end }}$ unless otherwise indicated (Table 2). Per our more rigorous validation of repolarization markings on stress days, we also assessed change in repolarization-related ECG parameters on stress days based on change from the 20-min pre-stress phase. QTc was calculated by the previously described murine- 
specific formula [116], which we adapted for rats as $\mathrm{QT} \div(\mathrm{RR} / 190)^{1 / 2}$ based on the average RR $(190 \mathrm{~ms})$ in the Air group across all analyzed exposure days.

We excluded arrhythmias ( $>18 \%$ reduction or $>25 \%$ increase in RR relative to the average of the prior $4 \mathrm{RRs}$ ) and, on select days, identified and quantified them as previously described [86] while blind to treatment and with verification by examination of concurrent LVP waveforms. ECG waveforms were analyzed in 5-min segments continuously over all BL days, select exposure days $(1,5,9,13,17,20,21)$, a recovery day (day 22$)$, and all stress test days. HRV analyses generated the timedomain variables SDNN and RMSSD, as well as the frequency-domain variables, HF $(0.75-3.50 \mathrm{~Hz}), \mathrm{LF}$ $(0.20-0.75 \mathrm{~Hz})$, and their ratio (LF/HF) as previously described [86, 94].

LVP signals were filtered of malformed waves, removing irregularly shaped contraction cycles as described [117], but with delineation in ecgAuto by removing all waveforms below $0.1 \%$ or above $99.9 \%$ the frequency distribution for LVEDP, LVESP, $d P / d t_{\max }$, CtrI $\left(d P / d t_{\max }\right.$ normalized by concurrent pressure to control for afterload), peak downslope in pressure $\left(d P / d t_{\text {min }}\right)$, and the lusitropic index, tau (the time required for $d P / d t_{\min }$ to reach half its value). Subsequently, any beats appearing as outliers in scatterplots of these parameters as well as software-defined begin diastolic pressure (BDP), begin systolic pressure (BSP), and maximum systolic pressure (maxSP), were visually inspected and removed if misshaped. To more thoroughly filter waveform distortions to ensure accurate slopes, we derived $d P / d t$ parameters after removal of beats with LVESP and BSP diverging by $>15 \mathrm{mmHg}$. All other pressure parameters were derived after additional removal of beats with $\mathrm{EDP}<-1 \mathrm{mmHg}$ to correct for rare instances of signal drift. CtrI is a particularly reliable afterload-independent marker of mechanical performance [35]. RT and tau reflect changes in lusitropy (diastolic function), albeit modestly, whereas $\mathrm{LV} d P / d t_{\max }$ and $d P / d t_{\min }$ are prohibitively sensitive to changes in afterload and preload [35]. Cycle lengths were assessed for ejection time (BSP-ESP interval) and relaxation time (ESP-EDP interval). One rat in the Air group was excluded from LVP endpoints on BL and inhalation exposure days due to recurrent abnormalities in pressure waveform morphology and amplitude. Because waveform morphology normalized after cessation of the PEPs exposure regimen but pressure amplitudes remained inconsistent, on stress test days this rat was excluded only from endpoints sensitive to pressure amplitude.

\section{Stress tests}

To further unmask any latent effects of PEPs on cardiac electrophysiology, we assessed ECG morphology and arrhythmia during and after a cold-water stress test. On stress test days $(2,27$, and 70 days after final PEPs exposure day), telemetry signals were acquired from rats in their home cages for $20 \mathrm{~min}$. Thereafter, animals were transferred to a rat cage with $2 \mathrm{~cm}$ deep ice-free chilled water $\left(1-3^{\circ} \mathrm{C}\right.$ maintained throughout stress) for $20 \mathrm{~min}$, and returned to their home cages for another $20 \mathrm{~min}$ [52]. Except where indicated otherwise (i.e., VPBs and select repolarization calculations), ECG and LVP parameters were normalized by the mean of BL days preceding inhalation exposure.

\section{Tissue collection}

On the days before and after the final stress test (10 weeks post-PEPs), rats were placed in metabolic chambers between 1000 and 1300 and urine collected and frozen immediately. Telemetered rats were euthanized and necropsied 2 days after the 10-week post-exposure stress test. Animals were fully anesthetized by $3 \%$ isoflurane and exsanguinated with blood collection from the abdominal aorta. Blood was collected in $\mathrm{K}_{2}$-EDTAbuffered collection tubes and spun at 3000 RPM, and plasma aliquots were collected and frozen at $-80^{\circ} \mathrm{C}$ immediately thereafter. Hearts were rapidly excised, placed on ice, rinsed free of blood with cooled saline, trimmed free of fat, longitudinally sectioned along the atrial axis, and one section placed in formalin fixative. For the remaining section, the RV was dissected from the LV and interventricular septum, and all tissues were placed in cryovials, snap-frozen in liquid nitrogen, and stored at $-80^{\circ} \mathrm{C}$ immediately thereafter.

\section{Analyses of urine, blood, and heart samples}

Urine was analyzed by an enzyme-linked immunosorbent assay (ELISA) kit for norepinephrine (Eagle Biosciences, NOU39-K010) and then analyzed for biogenic monoamines, including catecholamines and serotonin, using ultrahigh performance liquid chromatography with tandem mass spectrometry (UPLC-MS/MS) in the Metabolomics Core of the University of Louisville's Diabetes and Obesity Center as previously described [57]. For UPLC-MS/MS analysis of dopamine, norepinephrine (NE), epinephrine (EP), serotonin $(5-\mathrm{HT})$, and their metabolites (metanephrine $[\mathrm{MN}]$, normetanephrine [NMN], vanillylmandelic acid [VMA], 3-methoxytyramine [3-MT], and 5-hydroxyindole-3-acetic acid [5-HIAA]), urine samples were thawed on ice, vortexed and diluted 1 : 50 with $0.2 \%$ formic acid containing isotopic labeled internal standards. $1 \mu \mathrm{L}$ of mixture was analyzed on an UPLC-MS/MS instrument (ACQUITY UPLC H-Class system and Xevo TQ-S micro triple quadrupole mass spectrometer, all from Waters Inc., MA). Separation was performed on an Acquity UPLC HSS PFP $(150 \mathrm{~mm} \times 2.1$ $\mathrm{mm}, 1.8 \mu \mathrm{m}$ ) column (Waters Inc., MA) with a binary 
gradient comprised of $0.2 \%$ formic acid (Solvent A) and methanol (Solvent B). Three multiple reaction monitoring (MRM) transitions were set up for each sample: one for quantification, one for confirmation, and one for labeled internal standard. At least 12 data points were collected for each peak. Analytes were quantified using peak area ratio based on 8 point-standard curves run before and after the urine samples, and analyte concentrations were normalized by creatinine measured on a COBAS MIRAplus analyzer (Roche, NJ) with Infinity Creatinine Reagent (Thermo Fisher Scientific, MA). Blood was assayed for Btype natriuretic peptide (BNP-45, AssayPro ERB1202-1), n-terminal propeptide of atrial natriuretic peptide (NTproANP, Biomedica BI-20892), and cardiac troponin I (Life Diagnostics, CTNI-2-US Ultra-Sensitive Rat Cardiac Troponin-I) according to manufacturer-specified protocols. In a separate study, hearts from rats with chronic LVP implants identical to this study and exposed to filtered air in the same exposure system for 23 days were assessed for histopathological indications of hypertrophy and fibrosis relative to surgically-naïve control rats. Using Masson's trichrome we found that the chronic apical catheterization resulted in a small fibrotic lesion $(<2 \mathrm{~mm}$ diameter), but relative to surgically naïve rats there were no significant effects on cardiomyocyte area (mean \pm SEM: $510 \pm 28 \mu \mathrm{m}^{2}$ vs. $\left.488+24 \mu \mathrm{m}^{2}, P=0.45\right)$ or interstitial fibrosis $(1.5 \pm 0.1 \%$ vs. $1.1 \pm 0.1 \%, P=0.06)$ in the apical half of the LV, and no effects on the RV or the base of the heart, at 6-10 weeks post-surgery (unpublished data).

Right and left ventricles were separately homogenized in 1X RIPA buffer and immunoblot samples were made using Laemmli buffer with (or without) DTT (ThermoFisher). Equal amounts of protein $(10-30 \mu \mathrm{g})$ were first separated via agarose gel electrophoresis (7, 10\%, or AnyKd, BioRad) and then transferred wet to $0.2 \mu \mathrm{m}$ PVDF or nitrocellulose (BioRad, GE Healthcare) membranes. Membranes were blocked $1 \mathrm{~h}$ at RT with 5\% NFDM (Lab Scientific) before incubating overnight with primary antibody (1:250-1:5000 dilution, Cell Signaling [t-cTnI \#4002; p-cTnI \#4004; t-ERK \#9102; p-ERK \# 9101; t-Akt \# 9272; p-Akt \# 13038; GAPDH \#2118), Abcam [Cxn43/GJA1 \# ab11370; HO-1 \#ab13243; Myostatin/anti-GDF8 \#ab98337], Alamone [Kv1.5 \#APC-004; Kv4.2 \#APC-023; Kv4.3 \#APC-017; Kv7.1 \#APC-022], Santa Cruz [ $\beta 1-A R$ \#sc-568]) in either $5 \%$ BSA (Sigma) or 5\% NFDM per manufacturer recommendation. Membranes were washed in TBST and then incubated $1 \mathrm{~h}$ at RT in 1:2000 secondary antibody (anti-rabbit with HRP, Cell Signaling) in 5\% NFDM, then membranes were washed $3 \times 15 \mathrm{~min}$ prior to development and imaging. Membranes were developed in ECL (ThermoFisher), dried, and imaged in real-time using MyImager (ThermoFisher) according to manufacturer's protocol. All images were quantified in ImageJ, normalized to loading control. For Kv7.1 IP methods, see Supplement.

\section{Statistics}

We analyzed time-series deltas (each animal's change during exposure from the average of its four BL days) with linear mixed effects models (PROC MIXED) for day-specific or overall inhalant effects while controlling for day and selecting a random effects structure using AIC best fit criteria. Given their non-normal and longitudinal traits, we analyzed arrhythmia counts via generalized estimating equation (PROC GENMOD) as number of events per hour, assuming a Poisson distribution and exchangeable correlation structure. PROC REG was used to compare physiologic parameters (simple linear regression). Biochemical and molecular data were analyzed for group differences by two-tailed Student's ttest except for biogenic amines, for which we performed repeated measures two-way analysis of variance with Sidak multiple comparisons test and Grubbs test for outliers, which were excluded from this analysis. Statistical significance was assumed at $P<0.05$ between PEPs and Air control groups.

\section{Supplementary information}

Supplementary information accompanies this paper at https://doi.org/10. 1186/s12989-019-0335-z.

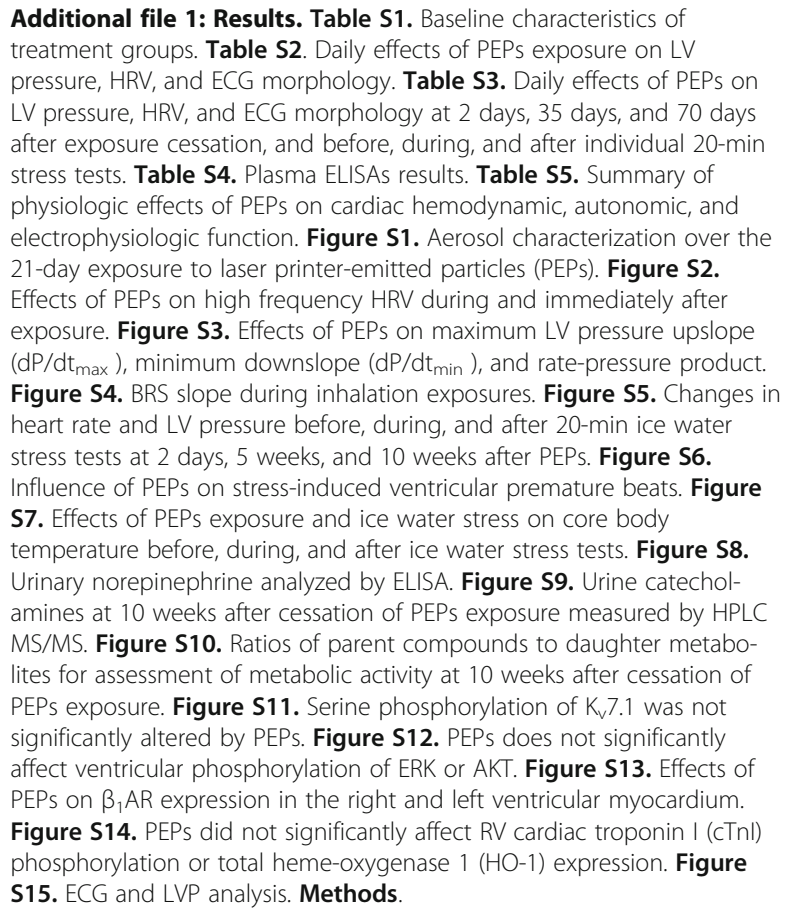
pressure, HRV, and ECG morphology. Table S3. Daily effects of PEPs on LV pressure, HRV, and ECG morphology at 2 days, 35 days, and 70 days after exposure cessation, and before, during, and after individual 20-min stress tests. Table S4. Plasma ELISAs results. Table S5. Summary of physiologic effects of PEPs on cardiac hemodynamic, autonomic, and electrophysiologic function. Figure S1. Aerosol characterization over the 21-day exposure to laser printer-emitted particles (PEPS). Figure S2. Effects of PEPS on high frequency HRV during and immediately after exposure. Figure S3. Effects of PEPS on maximum LV pressure upslope $\left(d P / d t_{\max }\right)$, minimum downslope $\left(d P / d t_{\min }\right)$, and rate-pressure product Figure S4. BRS slope during inhalation exposures. Figure S5. Changes in heart rate and LV pressure before, during, and after 20-min ice water stress tests at 2 days, 5 weeks, and 10 weeks after PEPs. Figure S6. Influence of PEPs on stress-induced ventricular premature beats. Figure S7. Effects of PEPs exposure and ice water stress on core body temperature before, during, and after ice water stress tests. Figure S8. Urinary norepinephrine analyzed by ELISA. Figure S9. Urine catecholamines at 10 weeks after cessation of PEPs exposure measured by HPLC MS/MS. Figure S10. Ratios of parent compounds to daughter metabolites for assessment of metabolic activity at 10 weeks after cessation of PEPS exposure. Figure S11. Serine phosphorylation of $K_{v} 7.1$ was not significantly altered by PEPs. Figure S12. PEPS does not significantly affect ventricular phosphorylation of ERK or AKT. Figure S13. Effects of PEPs on $\beta_{1} A R$ expression in the right and left ventricular myocardium. Figure S14. PEPs did not significantly affect RV cardiac troponin I (cTnl) phosphorylation or total heme-oxygenase $1(\mathrm{HO}-1)$ expression. Figure S15. ECG and LVP analysis. Methods.

\section{Abbreviations}

3-MT: 3-methoxytyramine; 5-HIAA: 5-hydroxyindole-3-acetic acid; 5HT: serotonin; BDP: begin diastolic pressure; BNP: B-type natriuretic peptide; BPM: beats per minute; BRS: baroreflex sensitivity; BSP: begin systolic pressure; COMT: catechol-O-methyltransferase; cTnl: cardiac troponin I; Ctrl: contractility index; CV: coefficient of variation; CVD: cardiovascular disease; devP: developed pressure; $d P / d t_{\max }$ : maximum rate of increase in left ventricular pressure per beat; $d P / d t_{\text {min }}$ : peak rate of decrease in left 
ventricular pressure per beat; DSI: DataSciences International; ECG: electrocardiogram; EjeT: ejection time; ELISA: enzyme-linked immunosorbent assay; EMC: electromechanical coupling time; ENMs: engineered nanomaterials; EP: epinephrine; GAPDH: glyceraldehyde-3phosphate dehydrogenase; GRK2: G-receptor kinase 2; GRKs: G-protein receptor kinases; GSD: geometric standard deviation; HEPA: high efficiency particulate air; HF: high frequency power spectral heart rate variability; HO1: heme-oxygenase 1; HR: heart rate; HRV: heart rate variability; HSPH: Harvard T.H. Chan School of Public Health; IACUC: Institutional Animal Care and Use Committee; LF: low frequency power spectral HRV; LQT: Long QT; LQT1: Long QT Syndrome 1; LV: left ventricle or left ventricular; LVEDP: left ventricular end diastolic pressure; LVESP: left ventricular end systolic pressure; LVP: left ventricular pressure; MAO: monoamine oxidase; maxSP: maximum systolic pressure; MN: metanephrine; MRM: multiple reaction monitoring; NE: norepinephrine; NMN: normetanephrine; PAHs: polycyclic aromatic hydrocarbons; Pdur: P-wave duration; PEGS: printer exposure generation system; PEPs: printer emitted particles; PM: particulate matter; pNN15: percentage of pairs of normal RR intervals with $>15 \mathrm{~ms}$ difference; ppb: parts per billion; proANP: pro-peptide of atrial natriuretic pepitide; QT: Q-Tend interval; QTc: corrected QT; QTp: Q-Tpeak interval; RMSSD: root mean squared of successive differences in RR intervals; RPM: rotations per minute; RT: relaxation time; RV: right ventricle or right ventricular; Samp: S amplitude; SDNN: standard deviation of normal RR intervals; ST neg area: negative ST area; Tamp: T amplitude; $T_{c o}$ : core body temperature; tVOCs: total volatile organic compounds; UPLC-MS/ MS: ultrahigh performance liquid chromatography with tandem mass spectrometry; VMA: vanillylmandelic acid; VOCs: volatile organic compounds; VPBs: ventricular premature beats; $\beta 1 A R: \beta_{1}$-adrenergic receptors.

\section{Acknowledgements}

The authors thank Dr. Nagarjun Konduru (Harvard) for animal handling and tissue collection, Mr. Bradley Anderson for animal handling and conducting animal telemetry sampling, Mr. Daniel Riggs (University of Louisville) for statistical review, and Mr. Kyle Fulghum (University of Louisville) for assistance in immunoblots and telemetry analyses. The authors also thank the National Institute of Occupational Safety and Health and the National Heart, Lung, and Blood Institute for their generous support.

\section{Authors' contributions}

APC designed, performed, and guided HRV, ECG, arrhythmia, and BRS analysis procedures, performed all statistical analyses, and wrote the manuscript. RS performed HRV, ECG, LVP, and arrhythmia analyses. SVP and YW oversaw acquisition of telemetry data and handled exposure engineering and aerosol characterization, and with $\mathrm{KB}$, processed and managed the aerosol characterization and data retrieval. ZX and PL performed UPLC MS/MS and related analyses on urine samples. NN performed molecular assays including Western blot, ELISAs, and immunoprecipitation. All authors read and approved of the final manuscript. YQ and VC participated in study design. JJG and PD performed study design with APC and oversaw execution of the study and manuscript preparation.

\section{Funding}

The authors acknowledge funding for this study from National Institute for Occupational Safety and Health (NIOSH) and Consumer Protection Safety Commission (CPSC) (Grant \# 212-2012-M-51174), National Institutes of Health (NIH) (Grant \# HL007118) and National Science Foundation (CBET\#1350789). Research reported in this publication was also supported by the National Heart, Lung, And Blood Institute of the National Institutes of Health (R01HL147343). The findings and conclusions in this report are those of the authors and do not necessarily represent the official positions of $\mathrm{NIH}$, the National Institute for Occupational Safety and Health, or the Centers for Disease Control and Prevention. RS was supported by the Coordenação de Aperfeiçoamento de Pessoal de Nível Superior - Brasil (CAPES) - Finance Code 001.

\section{Availability of data and materials}

Data supporting the findings are found within the manuscript and supplemental material. Raw data files will be provided by the corresponding author upon request.

\section{Ethics approval and consent to participate}

Harvard University's AAALAC International-accredited Institutional Animal Care and Use Committee approved all animal handling and experimental procedures. No human data were used for this study, and thus consent was not required.

\section{Consent for publication}

No human data were used for this study, and thus consent was not required.

\section{Competing interests}

The authors declare that they have no competing interests.

\section{Author details}

'Department of Physiology, School of Medicine, University of Louisville, Louisville, KY, USA. ${ }^{2}$ Christina Lee Brown Envirome Institute, University of Louisville, Louisville, KY, USA. ${ }^{3}$ Center for Nanotechnology and Nanotoxicology. Department of Environmental Health, T.H. Chan School of Public Health, Harvard University, 665 Huntington Avenue, Room 1310, Boston, MA 02115, USA. ${ }^{4}$ Department of Surgery, University of Sao Paulo Medical School, Sao Paulo, Brazil. ${ }^{5}$ Department of Occupational and Environmental Health Sciences,School of Public Health, Peking University, Beijing, People's Republic of China. ${ }^{6}$ Pathology and Physiology Research Branch, Health Effects Laboratory Division, National Institute for Occupational Safety and Health, Morgantown, WV, USA. ${ }^{7}$ Department of Pharmaceutical Sciences/Mary Babb Randolph Cancer Center, West Virginia University, Morgantown, WV, USA.

Received: 26 August 2019 Accepted: 29 December 2019 Published online: 29 January 2020

\section{References}

1. Lim SS, Vos T, Flaxman AD, Danaei G, Shibuya K, Adair-Rohani H, Amann M, Anderson HR, Andrews KG, Aryee M, et al. A comparative risk assessment of burden of disease and injury attributable to 67 risk factors and risk factor clusters in 21 regions, 1990-2010: a systematic analysis for the global burden of disease study 2010. Lancet. 2012;380(9859):2224-60.

2. Cohen AJ, Brauer M, Burnett R, Anderson HR, Frostad J, Estep K, Balakrishnan K, Brunekreef B, Dandona L, Dandona R, et al. Estimates and 25-year trends of the global burden of disease attributable to ambient air pollution: an analysis of data from the global burden of diseases study 2015. Lancet. 2017;389(10082):1907-18.

3. Brook RD, Rajagopalan S, Pope CA 3rd, Brook JR, Bhatnagar A, Diez-Roux AV, Holguin F, Hong Y, Luepker RV, Mittleman MA, et al. Particulate matter air pollution and cardiovascular disease: an update to the scientific statement from the American Heart Association. Circulation. 2010;121(21):2331-78.

4. Klepeis NE, Nelson WC, Ott WR, Robinson JP, Tsang AM, Switzer P, Behar JV, Hern SC, Engelmann WH. The National Human Activity Pattern Survey (NHAPS): a resource for assessing exposure to environmental pollutants. J Expo Anal Environ Epidemiol. 2001;11(3):231-52.

5. DeLoid GM, Wang Y, Kapronezai K, Lorente LR, Zhang R, Pyrgiotakis G, Konduru NV, Ericsson M, White JC, De La Torre-Roche R, et al. An integrated methodology for assessing the impact of food matrix and gastrointestinal effects on the biokinetics and cellular toxicity of ingested engineered nanomaterials. Part Fibre Toxicol. 2017;14(1):40.

6. Cohen JM, Derk R, Wang L, Godleski J, Kobzik L, Brain J, Demokritou P. Tracking translocation of industrially relevant engineered nanomaterials (ENMs) across alveolar epithelial monolayers in vitro. Nanotoxicology. 2014; 8(Suppl 1):216-25

7. Watson C, Ge J, Cohen J, Pyrgiotakis G, Engelward BP, Demokritou P. Highthroughput screening platform for engineered nanoparticle-mediated genotoxicity using CometChip technology. ACS Nano. 2014;8(3):2118-33.

8. Lu X, Miousse IR, Pirela SV, Moore JK, Melnyk S, Koturbash I, Demokritou P. In vivo epigenetic effects induced by engineered nanomaterials: a case study of copper oxide and laser printer-emitted engineered nanoparticles. Nanotoxicology. 2016;10(5):629-39.

9. Lu X, Miousse IR, Pirela SV, Melnyk S, Koturbash I, Demokritou P. Short-term exposure to engineered nanomaterials affects cellular epigenome. Nanotoxicology. 2016;10(2):140-50.

10. Konduru NV, Murdaugh KM, Swami A, Jimenez RJ, Donaghey TC, Demokritou P, Brain JD, Molina RM. Surface modification of zinc oxide 
nanoparticles with amorphous silica alters their fate in the circulation. Nanotoxicology. 2016;10(6):720-7.

11. Setyawati MI, Sevencan C, Bay BH, Xie J, Zhang Y, Demokritou P, Leong DT. Nano-TiO2 drives epithelial-Mesenchymal transition in intestinal epithelial Cancer cells. Small. 2018;14(30):e1800922.

12. Tsuda A, Venkata NK. The role of natural processes and surface energy of inhaled engineered nanoparticles on aggregation and Corona formation. Nanolmpact. 2016;2:38-44.

13. Sotiriou GA, Watson C, Murdaugh K, Darrah TH, Pyrgiotakis G, Elder A, Brain JD, Demokritou P. Engineering safer-by-design, transparent, silica-coated $\mathrm{ZnO}$ nanorods with reduced DNA damage potential. Environ Sci Nano. 2014;1(2):144-53.

14. DeLoid G, Casella B, Pirela S, Filoramo R, Pyrgiotakis G, Demokritou P, Kobzik $L$. Effects of engineered nanomaterial exposure on macrophage innate immune function. Nanolmpact. 2016;2:70-81.

15. Miller MR, Raftis JB, Langrish JP, McLean SG, Samutrtai P, Connell SP, Wilson S, Vesey AT, Fokkens PHB, Boere AJF, et al. Inhaled nanoparticles accumulate at sites of vascular disease. ACS Nano. 2017;11(5):4542-52.

16. Li Y, Lane KJ, Corlin L, Patton AP, Durant JL, Thanikachalam M, Woodin M, Wang M, Brugge D. Association of long-term near-highway exposure to ultrafine particles with cardiovascular diseases, diabetes and hypertension. Int J Environ Res Public Health. 2017;14(5):E461.

17. Samet JM, Rappold A, Graff D, Cascio WE, Berntsen JH, Huang YC, Herbst M, Bassett M, Montilla T, Hazucha MJ, et al. Concentrated ambient ultrafine particle exposure induces cardiac changes in young healthy volunteers. Am J Respir Crit Care Med. 2009;179(11):1034-42.

18. Sinharay R, Gong J, Barratt B, Ohman-Strickland P, Ernst S, Kelly FJ, Zhang JJ, Collins $P$, Cullinan $P$, Chung KF. Respiratory and cardiovascular responses to walking down a traffic-polluted road compared with walking in a traffic-free area in participants aged 60 years and older with chronic lung or heart disease and age-matched healthy controls: a randomised, crossover study. Lancet. 2018:391(10118):339-49.

19. Wang M, Utell MJ, Schneider A, Zareba W, Frampton MW, Oakes D, Hopke PK, Wiltshire J, Kane C, Peters A, et al. Does total antioxidant capacity modify adverse cardiac responses associated with ambient ultrafine, accumulation mode, and fine particles in patients undergoing cardiac rehabilitation? Environ Res. 2016;149:15-22.

20. Ahn S, Ardona HAM, Lind JU, Eweje F, Kim SL, Gonzalez GM, Liu Q, Zimmerman JF, Pyrgiotakis G, Zhang Z, et al. Mussel-inspired 3D fiber scaffolds for heart-on-a-chip toxicity studies of engineered nanomaterials. Anal Bioanal Chem. 2018;10:6141-54.

21. Pirela SV, Martin J, Bello D, Demokritou P. Nanoparticle exposures from nano-enabled toner-based printing equipment and human health: state of science and future research needs. Crit Rev Toxicol. 2017;47(8):678-704.

22. Pirela SV, Sotiriou GA, Bello D, Shafer M, Bunker KL, Castranova V, Thomas T, Demokritou P. Consumer exposures to laser printer-emitted engineered nanoparticles: a case study of life-cycle implications from nano-enabled products. Nanotoxicology. 2015;9(6):760-8.

23. Chalbot MG, Pirela SV, Schifman L, Kasaraneni V, Oyanedel-Craver V, Bello D, Castranova V, Qian Y, Thomas T, Kavouras IG, et al. Synergistic effects of engineered nanoparticles and organics released from laser printers using nano-enabled toners: potential health implications from exposures to the emitted organic aerosol. Environ Sci Nano. 2017;4(11):2144-56.

24. Pirela S, Molina R, Watson C, Cohen JM, Bello D, Demokritou P, Brain J. Effects of copy center particles on the lungs: a toxicological characterization using a Balb/c mouse model. Inhal Toxicol. 2013;25(9):498-508.

25. Pirela SV, Lu X, Miousse I, Sisler JD, Qian Y, Guo N, Koturbash I, Castranova V, Thomas T, Godleski J, et al. Effects of intratracheally instilled laser printeremitted engineered nanoparticles in a mouse model: a case study of toxicological implications from nanomaterials released during consumer use. Nanolmpact. 2016;1:1-8

26. Pirela SV, Miousse IR, Lu X, Castranova V, Thomas T, Qian Y, Bello D, Kobzik $L$, Koturbash I, Demokritou P. Effects of laser printer-emitted engineered nanoparticles on cytotoxicity, chemokine expression, reactive oxygen species, DNA methylation, and DNA damage: a comprehensive in vitro analysis in human small airway epithelial cells, macrophages, and Lymphoblasts. Environ Health Perspect. 2016;124(2):210-9.

27. Pirela SV, Pyrgiotakis G, Bello D, Thomas T, Castranova V, Demokritou P. Development and characterization of an exposure platform suitable for physico-chemical, morphological and toxicological characterization of printer-emitted particles (PEPs). Inhal Toxicol. 2014;26(7):400-8.
28. Sisler JD, Pirela SV, Friend S, Farcas M, Schwegler-Berry D, Shvedova A, Castranova V, Demokritou P, Qian Y. Small airway epithelial cells exposure to printer-emitted engineered nanoparticles induces cellular effects on human microvascular endothelial cells in an alveolar-capillary co-culture model. Nanotoxicology. 2015;9(6):769-79.

29. Bello D, Martin J, Santeufemio C, Sun Q, Lee Bunker K, Shafer M, Demokritou P. Physicochemical and morphological characterisation of nanoparticles from photocopiers: implications for environmental health. Nanotoxicology. 2013;7(5):989-1003.

30. Martin J, Bello D, Bunker K, Shafer M, Christiani D, Woskie S, Demokritou P. Occupational exposure to nanoparticles at commercial photocopy centers. J Hazard Mater. 2015;298:351-60.

31. Carll AP, Hazari MS, Perez CM, Krantz QT, King CJ, Haykal-Coates N, Cascio WE, Costa DL, Farraj AK. An autonomic link between inhaled diesel exhaust and impaired cardiac performance: insight from treadmill and dobutamine challenges in heart failure-prone rats. Toxicol Sci. 2013;135(2):425-36.

32. Wold LE, Ying Z, Hutchinson KR, Velten M, Gorr MW, Velten C, Youtz DJ, Wang A, Lucchesi PA, Sun Q, et al. Cardiovascular remodeling in response to long-term exposure to fine particulate matter air pollution. Circ Heart Fail. 2012;5(4):452-61.

33. Tankersley CG, Champion HC, Takimoto E, Gabrielson K, Bedja D, Misra V, ElHaddad H, Rabold R, Mitzner W. Exposure to inhaled particulate matter impairs cardiac function in senescent mice. Am J Physiol - Reg Integ Compar Physiol. 2008;295(1):R252.

34. Tankersley CG, Peng RD, Bedga D, Gabrielson K, Champion HC. Variation in echocardiographic and cardiac hemodynamic effects of PM and ozone inhalation exposure in strains related to $\mathrm{Nppa}$ and $\mathrm{Npr} 1$ gene knock-out mice. Inhal Toxicol. 2010;22(8):695-707.

35. Kijtawornrat A, Ueyama Y, del Rio C, Sawangkoon S, Buranakarl C, Chaiyabutr N, Hamlin RL. Test of the usefulness of a paradigm to identify potential cardiovascular liabilities of four test articles with varying pharmacological properties in anesthetized Guinea pigs. Toxicol Sci. 2014; 137(2):458-68

36. Biering-Sorensen T, Querejeta Roca G, Hegde SM, Shah AM, Claggett B, Mosley TH Jr, Butler KR Jr, Solomon SD. Left ventricular ejection time is an independent predictor of incident heart failure in a community-based cohort. Eur J Heart Fail. 2018;20(7):1106-14.

37. Teerlink JR. A novel approach to improve cardiac performance: cardiac myosin activators. Heart Fail Rev. 2009;14(4):289-98.

38. Devlin RB, Smith CB, Schmitt MT, Rappold AG, Hinderliter A, Graff D, Carraway MS. Controlled exposure of humans with metabolic syndrome to concentrated ultrafine ambient particulate matter causes cardiovascular effects. Toxicol Sci. 2014;140(1):61-72

39. Henneberger A, Zareba W, Ibald-Mulli A, Ruckerl R, Cyrys J, Couderc J, Mykins B, Woelke G, Wichmann HE, Peters A. Repolarization changes induced by air pollution in ischemic heart disease patients. Environ Health Perspect. 2005;113(4):440-6.

40. Liao D, Shaffer ML, Rodriguez-Colon S, He F, Li X, Wolbrette DL, Yanosky J, Cascio WE. Acute adverse effects of fine particulate air pollution on ventricular repolarization. Environ Health Perspect. 2010;118(7):1010-5.

41. Mordukhovich I, Kloog I, Coull B, Koutrakis P, Vokonas P, Schwartz J. Association between particulate air pollution and QT interval duration in an elderly cohort. Epidemiology. 2016;27(2):284-90.

42. Rich DQ, Zareba W, Beckett W, Hopke PK, Oakes D, Frampton MW, Bisognano J, Chalupa D, Bausch J, O'Shea K, et al. Are ambient ultrafine, accumulation mode and fine particles associated with adverse cardiac responses in patients undergoing cardiac rehabilitation? Environ Health Perspect. 2012;120(8):1162-9.

43. Tong H, Rappold AG, Diaz-Sanchez D, Steck SE, Berntsen J, Cascio WE, Devlin RB, Samet JM. Omega-3 fatty acid supplementation appears to attenuate particulate air pollution-induced cardiac effects and lipid changes in healthy middle-aged adults. Environ Health Perspect. 2012;120(7):952-7.

44. Zhang S, Breitner S, Cascio WE, Devlin RB, Neas LM, Diaz-Sanchez D, Kraus WE, Schwartz J, Hauser ER, Peters A, et al. Short-term effects of fine particulate matter and ozone on the cardiac conduction system in patients undergoing cardiac catheterization. Part Fibre Toxicol. 2018;15(1):38.

45. Carll AP, Lust RM, Hazari MS, Perez CM, Krantz QT, King CJ, Winsett DW, Cascio WE, Costa DL, Farraj AK. Diesel exhaust inhalation increases cardiac output, bradyarrhythmias, and parasympathetic tone in aged heart failureprone rats. Toxicol Sci. 2013;131(2):583-95.

46. Panikkath R, Reinier K, Uy-Evanado A, Teodorescu C, Hattenhauer J, Mariani R, Gunson K, Jui J, Chugh SS. Prolonged Tpeak-to-tend interval on the 
resting ECG is associated with increased risk of sudden cardiac death. Circ Arrhythm Electrophysiol. 2011;4(4):441-7.

47. Zhang Y, Post WS, Dalal D, Blasco-Colmenares E, Tomaselli GF, Guallar E. QTinterval duration and mortality rate: results from the third National Health and nutrition examination survey. Arch Intern Med. 2011;171(19):1727-33.

48. Shimizu M, Ino H, Okeie K, Yamaguchi M, Nagata M, Hayashi K, Itoh H, Iwaki T, Oe K, Konno T, et al. T-peak to T-end interval may be a better predictor of high-risk patients with hypertrophic cardiomyopathy associated with a cardiac troponin I mutation than QT dispersion. Clin Cardiol. 2002;25(7):335-9.

49. Shah RR. The significance of QT interval in drug development. Br J Clin Pharmacol. 2002;54(2):188-202.

50. Tankersley CG, Georgakopoulos D, Tang WY, Abston E, Bierman A, Sborz N. Effects of ozone and particulate matter on cardiac mechanics: role of the atrial natriuretic peptide gene. Toxicol Sci. 2013;131(1):95-107.

51. Ran J, Qiu H, Sun S, Yang A, Tian L. Are ambient volatile organic compounds environmental stressors for heart failure? Environ Pollut. 2018; 242(Pt B):1810-6.

52. Michalkiewicz M, Knestaut KM, Bytchkova EY, Michalkiewicz T. Hypotension and reduced catecholamines in neuropeptide $Y$ transgenic rats. Hypertension. 2003;41(5):1056-62.

53. Pirela SV, Bhattacharya K, Wang Y, Zhang YP, Wang GH, Christophi CA, Godleski J, Thomas T, Qian Y, Orandle MS, et al. A 21-day sub-acute, wholebody inhalation exposure to printer-emitted engineered nanoparticles in rats: exploring pulmonary and systemic effects. Nanoimpact. 2019;15: 100176.

54. Cvijic M, Antolic B, Klemen L, Zupan I. Repolarization heterogeneity in patients with cardiac resynchronization therapy and its relation to ventricular tachyarrhythmias. Heart Rhythm. 2018;15(12):1784-90.

55. Eisenhofer G, Kopin IJ, Goldstein DS. Catecholamine metabolism: a contemporary view with implications for physiology and medicine. Pharmacol Rev. 2004;56(3):331-49.

56. Huang $\mathrm{CL}$. The role of serotonin and possible interaction of serotoninrelated genes with alcohol dehydrogenase and aldehyde dehydrogenase genes in alcohol dependence-a review. Am J Transl Res. 2010;2(2):190-9.

57. Xie Z, Lorkiewicz P, Riggs DW, Bhatnagar A, Srivastava S. Comprehensive, robust, and sensitive UPLC-MS/MS analysis of free biogenic monoamines and their metabolites in urine. J Chromatogr B Anal Technol Biomed Life Sci. 2018;1099:83-91.

58. Wickenden AD, Jegla TJ, Kaprielian R, Backx PH. Regional contributions of Kv1.4, Kv4.2, and Kv4.3 to transient outward K+ current in rat ventricle. Am J Phys. 1999;276(5):H1599-607.

59. Tanabe Y, Hatada K, Naito N, Aizawa Y, Chinushi M, Nawa H, Aizawa Y. Overexpression of Kv1.5 in rat cardiomyocytes extremely shortens the duration of the action potential and causes rapid excitation. Biochem Biophys Res Commun. 2006:345(3):1116-21.

60. Nishiyama A, Kambe F, Kamiya K, Yamaguchi S, Murata Y, Seo H, Toyama J. Effects of thyroid and glucocorticoid hormones on Kv1.5 potassium channel gene expression in the rat left ventricle. Biochem Biophys Res Commun. 1997:237(3):521-6.

61. Lundby A, Andersen MN, Steffensen AB, Horn H, Kelstrup CD, Francavilla C, Jensen $L$, Schmitt N, Thomsen MB, Olsen JV. In vivo phosphoproteomics analysis reveals the cardiac targets of beta-adrenergic receptor signaling. Sci Signal. 2013;6(278):rs11

62. Horner JM, Horner MM, Ackerman MJ. The diagnostic utility of recovery phase QTc during treadmill exercise stress testing in the evaluation of long QT syndrome. Heart Rhythm. 2011;8(11):1698-704.

63. Shimizu W, Noda T, Takaki H, Nagaya N, Satomi K, Kurita T, Suyama K, Aihara N, Sunagawa K, Echigo S, et al. Diagnostic value of epinephrine test for genotyping LQT1, LQT2, and LQT3 forms of congenital long QT syndrome. Heart Rhythm. 2004;1(3):276-83.

64. Huang H, Amin V, Gurin M, Wan E, Thorp E, Homma S, Morrow JP. Dietinduced obesity causes long QT and reduces transcription of voltage-gated potassium channels. J Mol Cell Cardiol. 2013;59:151-8.

65. Carll AP, Farraj AK, Roberts AM. The role of the autonomic nervous system in cardiovascular toxicity. In: Campen MJ, editor. Comprehensive toxicology, vol. 13. 3rd ed. Oxford: Elsevier, Ltd.; 2018.

66. Martin J, Demokritou P, Woskie S, Bello D. Indoor air quality in photocopy centers, nanoparticle exposures at photocopy workstations, and the need for exposure controls. Ann Work Expo Health. 2017;61 (1):110-22.

67. La Rovere MT, Pinna GD, Hohnloser SH, Marcus FI, Mortara A, Nohara R, Bigger JT Jr, Camm AJ, Schwartz PJ, Tone AIA, et al. Baroreflex sensitivity and heart rate variability in the identification of patients at risk for lifethreatening arrhythmias: implications for clinical trials. Circulation. 2001; 103(16):2072-7.

68. Benjamin EJ, Virani SS, Callaway CW, Chamberlain AM, Chang AR, Cheng S, Chiuve SE, Cushman M, Delling FN, Deo R, et al. Heart disease and stroke statistics-2018 update: a report from the American Heart Association. Circulation. 2018;137(12):e67-e492.

69. Kurhanewicz N, McIntosh-Kastrinsky R, Tong H, Walsh L, Farraj AK, Hazari MS Ozone co-exposure modifies cardiac responses to fine and ultrafine ambient particulate matter in mice: concordance of electrocardiogram and mechanical responses. Part Fibre Toxicol. 2014;11:54.

70. Hardy ST, Loehr LR, Butler KR, Chakladar S, Chang PP, Folsom AR, Heiss G, MacLehose RF, Matsushita K, Avery CL. Reducing the blood pressure-related burden of cardiovascular disease: impact of achievable improvements in blood pressure prevention and control. J Am Heart Assoc. 2015;4(10):e002276.

71. Accardi MV, Troncy E, Abtout S, Ascah A, Maghezzi S, Authier S. Rat cardiovascular telemetry: marginal distribution applied to positive control drugs. J Pharmacol Toxicol Methods. 2016;81:120-7.

72. Holmes JC, Fowler NO. Direct cardiac effects of dopamine. Circ Res. 1962;10:68-72.

73. Horwitz D, Goldberg LI, Sjoerdsma A. Increased blood pressure responses to dopamine and norepinephrine produced by monoamine oxidase inhibitors in man. J Lab Clin Med. 1960;56:747-53.

74. Orgacka OH, Ryszka F, Zych F. Excretion of Catechoalmines by children exposed to atmospheric pollution in the province of Katowice. Acta Phys Pol A. 1983;34(1):11

75. Hajat A, Diez Roux AV, Castro-Diehl C, Cosselman K, Golden SH, Hazlehurst MF, Szpiro A, Vedal S, Kaufman JD. The association between Long-term air pollution and urinary Catecholamines: evidence from the multi-ethnic study of atherosclerosis. Environ Health Perspect. 2019:127(5):57007.

76. Li H, Cai J, Chen R, Zhao Z, Ying Z, Wang L, Chen J, Hao K, Kinney PL, Chen $H$, et al. Particulate matter exposure and stress hormone levels: a randomized, double-blind, crossover trial of air purification. Circulation. 2017;136(7):618-27.

77. Costentin J, Duterte-Boucher D, Panissaud C, Michael-Titus A. Dopamine D1 and D2 receptors mediate opposite effects of apomorphine on the body temperature of reserpinized mice. Neuropharmacology. 1990;29(1):31-5.

78. Sedaghat $K$, Tiberi M. Cytoplasmic tail of D1 dopaminergic receptor differentially regulates desensitization and phosphorylation by $\mathrm{G}$ proteincoupled receptor kinase 2 and 3. Cell Signal. 2011;23(1):180-92.

79. Lu X, Ye Z, Zheng S, Ren H, Zeng J, Wang X, Jose PA, Chen K, Zeng C. Long-term exposure of fine particulate matter causes hypertension by impaired renal D1 receptor-mediated sodium excretion via upregulation of G-protein-coupled receptor kinase type 4 expression in sprague-dawley rats. J Am Heart Assoc. 2018;7(1):e007185.

80. de Hartog JJ, Lanki T, Timonen KL, Hoek G, Janssen NA, Ibald-Mulli A, Peters A, Heinrich J, Tarkiainen TH, van Grieken R, et al. Associations between PM2. 5 and heart rate variability are modified by particle composition and betablocker use in patients with coronary heart disease. Environ Health Perspect. 2009;117(1):105.

81. Dockery DW, Luttmann-Gibson H, Rich DQ, Link MS, Mittleman MA, Gold $D R$, Koutrakis P, Schwartz JD, Verrier RL. Association of air pollution with increased incidence of ventricular tachyarrhythmias recorded by implanted cardioverter defibrillators. Environ Health Perspect. 2005;113(6):670-4.

82. Timonen KL, Vanninen E, de Hartog J, Ibald-Mulli A, Brunekreef B, Gold DR, Heinrich J, Hoek G, Lanki T, Peters A, et al. Effects of ultrafine and fine particulate and gaseous air pollution on cardiac autonomic control in subjects with coronary artery disease: the ULTRA study. J Expo Sci Environ Epidemiol. 2006;16(4):332.

83. Robertson S, Thomson AL, Carter R, Stott HR, Shaw CA, Hadoke PW, Newby $D E$, Miller MR, Gray GA. Pulmonary diesel particulate increases susceptibility to myocardial ischemia/reperfusion injury via activation of sensory TRPV1 and beta1 adrenoreceptors. Part Fibre Toxicol. 2014;11:12.

84. Huynh QL, Blizzard CL, Marwick TH, Negishi K. Association of ambient particulate matter with heart failure incidence and all-cause readmissions in Tasmania: an observational study. BMJ Open. 2018;8(5):e021798.

85. DiCarlo SE, Bishop VS. Central baroreflex resetting as a means of increasing and decreasing sympathetic outflow and arterial pressure. Ann N Y Acad Sci. 2001;940:324-37.

86. Carll AP, Crespo SM, Filho MS, Zati DH, Coull BA, Diaz EA, Raimundo RD, Jaeger TNG, Ricci-Vitor AL, Papapostolou V, et al. Inhaled ambient-level 
traffic-derived particulates decrease cardiac vagal influence and baroreflexes and increase arrhythmia in a rat model of metabolic syndrome. Part Fibre Toxicol. 2017;14(1):16.

87. Szydlo K, Wita K, Trusz-Gluza M, Tabor Z. Late phase of repolarization (TpeakTend) as a prognostic marker of left ventricle remodeling in patients with anterior myocardial infarction treated with primary coronary intervention. Cardiol J. 2010;17(3):244-8.

88. Cavallari JM, Fang SC, Eisen EA, Mittleman MA, Christiani DC. Environmental and occupational particulate matter exposures and ectopic heart beats in welders. Occup Environ Med. 2016;73(7):435-41.

89. He F, Shaffer ML, Rodriguez-Colon S, Yanosky JD, Bixler E, Cascio WE, Liao D. Acute effects of fine particulate air pollution on cardiac arrhythmia: the APACR study. Environ Health Perspect. 2011;119(7):927-32.

90. O'Neal WT, Soliman EZ, Efird JT, Howard VJ, Howard G, McClure LA. Fine particulate air pollution and premature ventricular contractions: the REasons for geographic and racial differences in stroke (REGARDS) study. Environ Res. 2017;154:115-9.

91. Rich DQ, Schwartz J, Mittleman MA, Link M, Luttmann-Gibson H, Catalano PJ, Speizer FE, Dockery DW. Association of short-term ambient air pollution concentrations and ventricular arrhythmias. Am J Epidemiol. 2005;161(12):1123-32.

92. Kang SH, Heo J, Oh IY, Kim J, Lim WH, Cho Y, Choi EK, Yi SM, Do Shin S, Kim $\mathrm{H}$, et al. Ambient air pollution and out-of-hospital cardiac arrest. Int J Cardiol. 2016;203:1086-92.

93. Teng $T H$, Williams TA, Bremner A, Tohira H, Franklin P, Tonkin A, Jacobs I, Finn J. A systematic review of air pollution and incidence of out-of-hospital cardiac arrest. J Epidemiol Community Health. 2014;68(1):37-43.

94. Carll AP, Haykal-Coates N, Winsett DW, Hazari MS, Ledbetter AD, Richards $\mathrm{JH}$, Cascio WE, Costa DL, Farraj AK. Cardiomyopathy confers susceptibility to particulate matter-induced oxidative stress, vagal dominance, arrhythmia and pulmonary inflammation in heart failure-prone rats. Inhal Toxicol. 2015; 27(2):100-12.

95. Carll AP, Haykal-Coates N, Winsett DW, Rowan WH 3rd, Hazari MS, Ledbetter AD, Nyska A, Cascio WE, Watkinson WP, Costa DL, et al. Particulate matter inhalation exacerbates cardiopulmonary injury in a rat model of isoproterenol-induced cardiomyopathy. Inhal Toxicol. 2010;22(5):355-68.

96. Carll AP, Hazari MS, Perez CM, Krantz QT, King CJ, Winsett DW, Costa DL, Farraj AK. Whole and particle-free diesel exhausts differentially affect cardiac electrophysiology, blood pressure, and autonomic balance in heart failureprone rats. Toxicol Sci. 2012;128(2):490-9.

97. Farraj AK, Haykal-Coates N, Winsett DW, Hazari MS, Carll AP, Rowan WH Ledbetter AD, Cascio WE, Costa DL. Increased non-conducted P-wave arrhythmias after a single oil fly ash inhalation exposure in hypertensive rats. Environ Health Perspect. 2009;117(5):709.

98. Farraj AK, Hazari MS, Haykal-Coates N, Lamb C, Winsett DW, Ge Y, Ledbetter AD, Carll AP, Bruno M, Ghio A, et al. ST depression, arrhythmia, vagal dominance, and reduced cardiac micro-RNA in particulate-exposed rats. Am J Respir Cell Mol Biol. 2011;44(2):185-96.

99. Anselme F, Loriot S, Henry JP, Dionnet F, Napoleoni JG, Thuillez C, Morin JP. Inhalation of diluted diesel engine emission impacts heart rate variability and arrhythmia occurrence in a rat model of chronic ischemic heart failure. Arch Toxicol. 2007;81(4):299-307.

100. Wellenius G, Saldiva P, Batalha J, Murthy G, Coull B, Verrier R, Godleski J. Electrocardiographic changes during exposure to residual oil fly ash (ROFA) particles in a rate model of myocardial infarction. Toxicol Sci. 2002;66:327-35.

101. Wellenius GA, Diaz EA, Gupta T, Ruiz PA, Long M, Kang CM, Coull BA, Godleski JJ. Electrocardiographic and respiratory responses to coal-fired power plant emissions in a rat model of acute myocardial infarction: results from the toxicological evaluation of realistic emissions of source aerosols study. Inhal Toxicol. 2011;23(Suppl 2):84-94.

102. Wang T, Lang GD, Moreno-Vinasco L, Huang Y, Goonewardena SN, Peng YJ, Svensson EC, Natarajan V, Lang RM, Linares JD, et al. Particulate matter induces cardiac arrhythmias via dysregulation of carotid body sensitivity and cardiac sodium channels. Am J Respir Cell Mol Biol. 2012;46(4):524-31.

103. Scott PA, Rosengarten JA, Shahed A, Yue AM, Murday DC, Roberts PR, Peebles CR, Harden SP, Curzen NP, Morgan JM. The relationship between left ventricular scar and ventricular repolarization in patients with coronary artery disease: insights from late gadolinium enhancement magnetic resonance imaging. Europace. 2013;15(6):899-906.
104. Xu H, Zhao M, Liang S, Huang Q, Xiao Y, Ye L, Wang Q, He L, Ma L, Zhang $\mathrm{H}$, et al. The effects of Puerarin on rat ventricular Myocytes and the potential mechanism. Sci Rep. 2016;6:35475.

105. Schwartz PJ, Priori SG, Spazzolini C, Moss AJ, Vincent GM, Napolitano C, Denjoy I, Guicheney P, Breithardt G, Keating MT, et al. Genotype-phenotype correlation in the long-QT syndrome: gene-specific triggers for lifethreatening arrhythmias. Circulation. 2001;103(1):89-95.

106. Boukens BJ, Sulkin MS, Gloschat CR, Ng FS, Vigmond EJ, Efimov IR. Transmural APD gradient synchronizes repolarization in the human left ventricular wall. Cardiovasc Res. 2015;108(1):188-96.

107. Meijborg VM, Conrath CE, Opthof T, Belterman CN, de Bakker JM, Coronel R. Electrocardiographic T wave and its relation with ventricular repolarization along major anatomical axes. Circ Arrhythm Electrophysiol. 2014;7(3):524-31.

108. Layland J, Solaro RJ, Shah AM. Regulation of cardiac contractile function by troponin I phosphorylation. Cardiovasc Res. 2005;66(1):12-21.

109. Montgomery DE, Wolska BM, Pyle WG, Roman BB, Dowell JC, Buttrick PM, Koretsky AP, Del Nido P, Solaro RJ. Alpha-adrenergic response and myofilament activity in mouse hearts lacking PKC phosphorylation sites on cardiac Tnl. Am J Physiol Heart Circ Physiol. 2002;282(6):H2397-405.

110. Constantinides $C$, Mean $R$, Janssen BJ. Effects of isoflurane anesthesia on the cardiovascular function of the C57BL/6 mouse. ILAR J. 2011;52(3):e21-31.

111. Costa DL, Dreher KL. Bioavailable transition metals in particulate matter mediate cardiopulmonary injury in healthy and compromised animal models. Environ Health Perspect. 1997;105(Suppl 5):1053-60.

112. Lee MS, Magari S, Christiani DC. Cardiac autonomic dysfunction from occupational exposure to polycyclic aromatic hydrocarbons. Occup Environ Med. 2011;68(7):474-8.

113. Lippmann M, Ito K, Hwang JS, Maciejczyk P, Chen LC. Cardiovascular effects of nickel in ambient air. Environ Health Perspect. 2006;1 14(11):1662-9.

114. Graff DW, Cascio WE, Brackhan JA, Devlin RB. Metal particulate matter components affect gene expression and beat frequency of neonatal rat ventricular myocytes. Environ Health Perspect. 2004;112(7):792-8.

115. Diaz EA, Lemos M, Coull B, Long MS, Rohr AC, Ruiz P, Gupta T, Kang CM, Godleski JJ. Toxicological evaluation of realistic emission source aerosols (TERESA)--power plant studies: assessment of breathing pattern. Inhal Toxicol. 2011;23(Suppl 2):42-59.

116. Mitchell GF, Jeron A, Koren G. Measurement of heart rate and Q-T interval in the conscious mouse. Am J Phys. 1998;274(3 Pt 2):H747-51.

117. Stehlin E, Malpas SC, Budgett DM, Barrett CJ, McCormick D, Whalley G, Fu F, Beil M, Rigel DF, Guild SJ. Chronic measurement of left ventricular pressure in freely moving rats. J Appl Physiol (1985). 2013;115(11):1672-82.

\section{Publisher's Note}

Springer Nature remains neutral with regard to jurisdictional claims in published maps and institutional affiliations.

Ready to submit your research? Choose BMC and benefit from:

- fast, convenient online submission

- thorough peer review by experienced researchers in your field

- rapid publication on acceptance

- support for research data, including large and complex data types

- gold Open Access which fosters wider collaboration and increased citations

- maximum visibility for your research: over $100 \mathrm{M}$ website views per year

At BMC, research is always in progress.

Learn more biomedcentral.com/submissions 